\title{
Three-Dimensional Finite Element Modeling of Thermomechanical Problems in Functionally Graded Hydroxyapatite/Titanium Plate
}

\author{
S. N. S. Jamaludin, ${ }^{1}$ S. Basri, ${ }^{1}$ Ahmad Hussain, ${ }^{2}$ Dheya Shujaa Al-Othmany, \\ F. Mustapha, ${ }^{3}$ and D. M. Nuruzzaman ${ }^{1}$ \\ ${ }^{1}$ Faculty of Manufacturing Engineering, Universiti Malaysia Pahang, Pekan, Pahang 26600, Malaysia \\ ${ }^{2}$ Department of Nuclear Engineering, King Abdulaziz University, Jeddah 21589, Saudi Arabia \\ ${ }^{3}$ Department of Aerospace Engineering, Universiti Putra Malaysia, Serdang, Selangor 43400, Malaysia \\ Correspondence should be addressed to S. N. S. Jamaludin; snursakinah@gmail.com
}

Received 14 November 2013; Revised 14 February 2014; Accepted 14 February 2014; Published 10 April 2014

Academic Editor: Kim Meow Liew

Copyright ( $\odot 2014$ S. N. S. Jamaludin et al. This is an open access article distributed under the Creative Commons Attribution License, which permits unrestricted use, distribution, and reproduction in any medium, provided the original work is properly cited.

\begin{abstract}
The composition of hydroxyapatite (HA) as the ceramic phase and titanium (Ti) as the metallic phase in HA/Ti functionally graded materials (FGMs) shows an excellent combination of high biocompatibility and high mechanical properties in a structure. Because the gradation of these properties is one of the factors that affects the response of the functionally graded (FG) plates, this paper is presented to show the domination of the grading parameter on the displacement and stress distribution of the plates. A threedimensional (3D) thermomechanical model of a 20 -node brick quadratic element is used in the simulation of the thermoelastic behaviors of HA/Ti FG plates subjected to constant and functional thermal, mechanical, and thermomechanical loadings. The convergence properties of the present results are examined thoroughly in order to assess the accuracy of the theory applied and to compare them with the established research results. Instead of the grading parameter, this study reveals that the loading field distribution can be another factor that reflects the thermoelastic properties of the HA/Ti FG plates. The FG structure is found to be able to withstand the thermal stresses while preserving the high toughness properties and thus shows its ability to operate at high temperature.
\end{abstract}

\section{Introduction}

The term functionally graded (FG) is used to refer to inhomogeneous advanced composite materials in which the composition percentage of at least two materials is arranged to vary from one surface to another surface in a structure [1]. The properties' gradients produced from the volume fraction variation may be tailored to meet specific needs while providing the best utilization of the composite components. The notion of functionally graded materials (FGMs) was introduced in the early 1990s in Japan as a means of overcoming problems concerning heat-resistant coatings in aerospace applications [2]. The development of the relatively advanced materials was then further extended to other fields of applications, including thermoelectric and piezoelectric devices [3], biomedical engineering [4], and nuclear fast breeder and fusion reactors [5], because of their phenomenological properties. This technology has somewhat mitigated performance issues arising from abrupt transitions between dissimilar materials, namely, sharp interfaces due to adhesion that induces substantial mechanical and thermal stresses [6]. Therefore, the optimal processing technique in which several methods are combined based on the properties of the constituent materials should be implemented [7]. The best combination will preserve the high performance of the fabricated FGMs and, at the same time, reduce production costs.

A key philosophy in selecting the composition for an FGM is that the combination should be composed of the attractive properties of each component. Hydroxyapatite 
(HA)/titanium (Ti) FGM is a good example of this, where the excellent biocompatibility property of HA is combined with the good mechanical properties of $\mathrm{Ti}$ to eliminate the weakness of both materials. The combination somehow provides a structure superior to either component alone. In this study, the thermoelastic properties of the HA/Ti FG plate are explored by looking at the atomic or microscopic scale of the structure. The response of the plate due to thermal and mechanical loadings is analyzed within the consideration of various grading parameter values. In a microscopic scale, the architecture of the FGMs is contrasted against the surrounding matrix of pure materials. This factor leads to various responses in displacement and stress fields when the materials are imposed on different loading conditions.

The effect of radial and normal loads under thermal excitation on the postbuckling response of a shear deformable FG cylindrical shell has been analyzed using a singular perturbation technique in which a higher shear deformation shell theory was applied. The study concluded that the properties' variation along the thickness direction of the FG shell and the temperature field distribution are the two parameters that affect the postbuckling characteristics and the imperfection sensitivity of the shell [8]. Matsunaga [9] developed a two-dimensional (2D) model using a higherorder deformation theory to analyze the response of FG plates subjected to thermal and mechanical loads. In the computation, equations that consider the effect of normal and transverse shear stress were derived using the power series expansion of the continuous displacement components method. The study revealed that the effect of the properties' variation along the thickness of the FG plate is larger on the response of FG plates subjected to thermal loadings. The effects of thermal and mechanical loads on the response of simply supported rectangular FG plates have been analyzed using a three-dimensional (3D) thermoelastic model based on the Fourier series and state-space methods [10]. The material properties of the FG plates were assumed to vary exponentially along the thickness direction except for the Poisson ratio, which was taken as constant. It is mentioned that the location of the neutral surface is different from that of the middle surface but reflected in the Young modulus variation. The research results in Alibeigloo [10] show that the contribution of the thermal loads on the thermoelastic response of the FG plates is bigger than that of mechanical loads. The effects of thermomechanical loading on the buckling response of FG beams were analyzed by Kiani and Eslami [11] using a derivation of the Timoshenko beam theory. In the analysis, various types of boundary conditions including clamps, simply supported, and roller combination were taken into account to observe the response field distribution. This study revealed that the critical buckling temperature field is greatly affected by the constituent temperature dependency. A local meshless method based on the Petrov-Galerkin approach with moving Kriging interpolation has been used to solve large deformation problems in the geometrically nonlinear thermomechanical analysis of moderately thick FG plates. The study revealed that the thermal conductivity on temperature does affect the stress field analysis on the FG plates [12]. The same local Kriging meshless method has

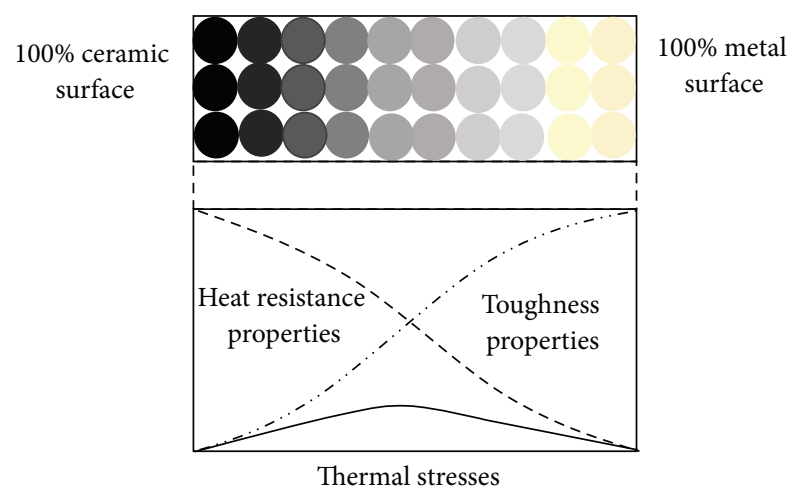

FIgUre 1: Concept of FGM [16].

been used for mechanical and thermal buckling analyses of FG plates in an extended numerical work. The analyses show the dependency of the FG plates' buckling performances on the volume fraction exponent under thermal and mechanical loadings with different combined essential conditions and loading conditions [13]. The element-free kpRitz method combined with the first-order shear deformation shell theory and von Kármán strains is another approach used for a postbuckling analysis of CNTR-FG (carbon nanotube reinforced functionally graded) cylindrical panels. The influence of volume fraction, length-to-thickness ratio, radius, boundary conditions, and distribution types of CNTs on the postbuckling behavior of the CNTR-FG panels are shown in this study [14]. An extended work on the static and dynamic analyses on the CNTR-FG cylindrical panels revealed that the influencing parameters studied in the earlier paper have significant influences on the flexural strength and free vibration responses of the panels [15].

In this paper, the authors will take a closer look at HA/Ti FGMs and their behavior under different loading conditions. The mechanical, thermal, and coupled thermomechanical behavior of HA/Ti FGMs will be investigated using the finite element method (FEM). The thermomechanical behavior of HA/Ti FGM plates is examined for different loading conditions and different volume fraction indices. The present accomplished results are verified and compared with published works available in the literature. The obtained results are presented in the form of contours, tables, and figures to show the parametric effects such as grading parameter and load response, which can be treated as a benchmark for future and advanced research work. These results are significant from the point of view of developing and designing thermal barrier materials, which are capable of withstanding extreme surface temperature.

\section{Theoretical Formulations}

The basic concept of FGMs, which produces the compositional changes in the constituents, is illustrated in Figure 1 [16]. FGMs with high mechanical properties on one side of the structures and with perfect thermal resistance properties 


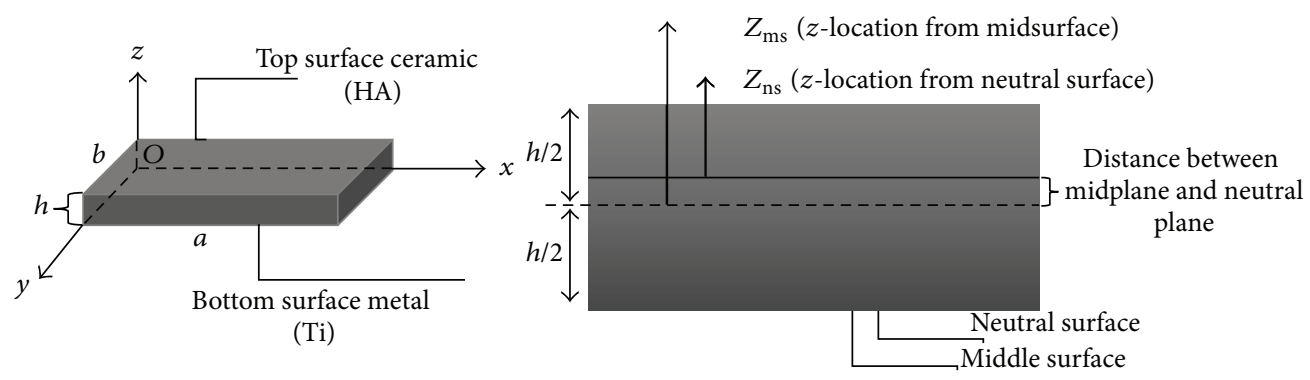

FIGURE 2: FG plate configuration and coordinates.

on the other side are advantageous for various thermalresistant applications. Several advantages involving the structural strength, energy conversion, and others have been identified using different FGM combinations [17]. The main advantage of FGMs in terms of thermomechanical problems is that the alternately changed properties within their structures act as a suspension of plastic yield point and failure due to thermomechanical loads $[18,19]$. The gradation process is the key element to identify the utility of FGMs. The gradual change of properties in FGMs is caused by a position-dependent chemical composition, the geometric configuration, the pore size distribution, or the physical state arrangement.

A simply supported rectangular FG plate of length $a$, width $b$, and thickness $h$ with a Cartesian coordinate system $(O x y z)$ having the origin $O$ considered in this study is displayed in Figure 2. The material properties of the structure are assumed to vary in the thickness direction, which is represented by the $z$-coordinate while homogeneous in the other two remaining $x$ and $y$ directions. The ceramic-rich and metal-rich phases in the FGM are represented by the top location $(Z=h / 2)$ and the bottom location $(Z=-h / 2)$, respectively.

The typical material properties $(P)$ at an arbitrary location within the structural domain are calculated based on the rule of mixture [20-23], which is expressed in the following equation:

$$
P=\left(P_{t}-P_{b}\right) V_{f}+P_{b}
$$

In the equation, $P_{t}$ and $P_{b}$ are the top and the bottom surface material properties, respectively, while $V_{f}$ is the volume fraction of the top surface material of the FGM plate. The Poisson ratio of each layer is assumed to be constant [24] because the effect of the properties' variation is negligible for a unit of structure. It is noticed that most FGMs are constructed with the ceramic phase at the top surface because metal with its high toughness could be more suitable to support the structure from the bottom side. The location of each composed material should be precisely identified in order to get accurate material properties according to the rule of mixture. The following equation is used for the calculation of the volume fraction of any phase of the composed materials:

$$
V_{f}=\left(\frac{Z}{h}+0.5\right)^{n}
$$

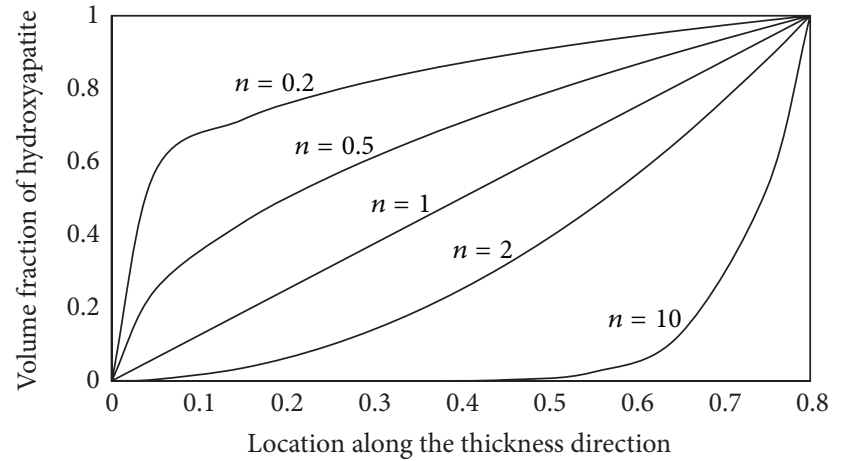

FIGURE 3: Ceramic volume fraction along the thickness of the FG plate.

where $Z$ is the coordinate at the $z$-direction of the plate and $n$ is the grading parameter that dictates the properties' variation. The FGMs will have a homogeneous ceramic ingredient when $n=0$ and a homogeneous metal ingredient when $n=\infty$. The properties' variation along the thickness direction of the plate is only available when the grading parameter is between these two values. The volume fraction of the composed materials strongly depends on the grading parameter, $n$, as summarized in Figure 3. This parameter somehow leads to either ceramic or metal phase domination in terms of the volume fraction in the FG structure. The grading parameter $n=1$ shows the balance or linear mixing ratio between the constituents. The mixing ratio of the composed materials can be interpreted in terms of the percentage according to the following expression:

$$
V_{t}(z)+V_{b}(z)=1
$$

where $V_{t}$ and $V_{b}$ represent the top and the bottom surface material volume fraction, respectively.

In order to determine the stress distribution within the FG plate, it is necessary to analyze the deformation that takes place in any location of the structure. In this study, the HA/Ti FG plate geometry is meshed up using a 20-node brick element to divide the structure into finite elements. The main reason for choosing this element type is that it can analyze curved boundaries using a piecewise-quadratic 


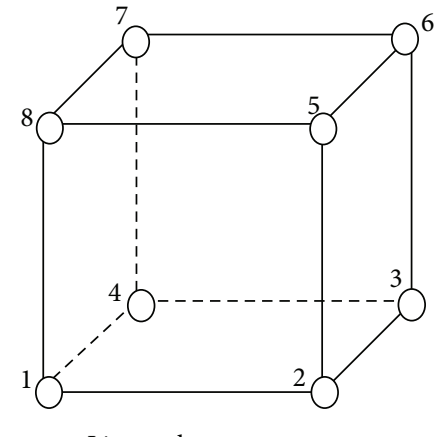

Linear element

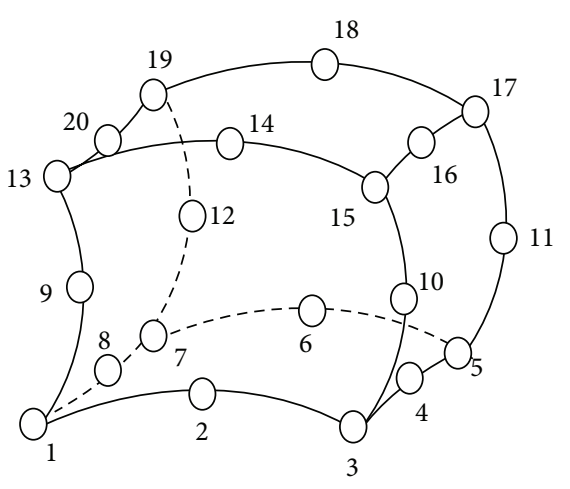

Quadratic element

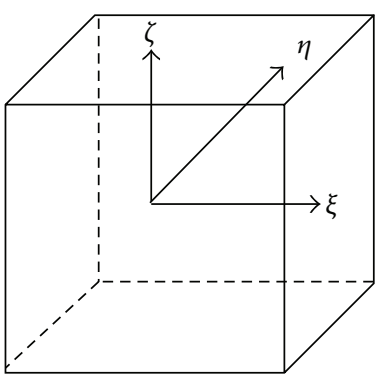

FigURE 4: 20-node brick element.

approximation. The shape functions for the 20-node quadratic element can be expressed as follows:

$$
\begin{aligned}
& N_{i}=\frac{1}{8}\left(1+\xi_{0}\right)\left(1+\eta_{0}\right)\left(1+\zeta_{0}\right)\left(\xi_{0}+\eta_{0}+\zeta_{0}-2\right) \text { vertices } \\
& N_{i}=\frac{1}{4}\left(1+\xi^{2}\right)\left(1+\eta_{0}\right)\left(1+\zeta_{0}\right), \quad i=2,6,14,18 \\
& N_{i}=\frac{1}{4}\left(1+\eta^{2}\right)\left(1+\eta_{0}\right)\left(1+\zeta_{0}\right), \quad i=4,8,16,20 \\
& N_{i}=\frac{1}{4}\left(1+\zeta^{2}\right)\left(1+\eta_{0}\right)\left(1+\zeta_{0}\right), \quad i=9,10,11,12 .
\end{aligned}
$$

In these equations, $\xi_{i}, \eta_{i}$, and $\zeta_{i}$ refer to the values of the local coordinates $\xi, \eta$, and $\zeta$ at nodes. $N$ refers to the matrix of the shape functions, which can be written as follows:

$$
[N]=\left[\begin{array}{ccccccc}
N_{1} & 0 & 0 & N_{2} & 0 & 0 & \cdots \\
0 & N_{1} & 0 & 0 & N_{2} & 0 & \cdots \\
0 & 0 & N_{1} & 0 & 0 & N_{2} & \cdots
\end{array}\right]
$$

The polynomials of these coordinates $(-1 \leq \xi, \eta, \zeta \leq$ 1) are the shape function used for the interpolation of the geometry and displacement field. The isoparametric element of the 20-node brick type in the simulation of this study is shown in Figure 4. It is indicated that the nodes of this element type are located at the vertices and in the middle of the edges.

For 3D isoparametric elements including the 20-node brick type, the displacement and the geometry field are related by interpolation using the same functions such as the following:

$$
\begin{gathered}
\{x\}=[N]\left\{x^{e}\right\} \\
\{x\}=\{x \quad y \quad z\} \\
\left\{x^{e}\right\}=\left\{x_{1} y_{1} z_{1} x_{2} y_{2} z_{2} \ldots\right\},
\end{gathered}
$$

where $x, y$, and $z$ are point coordinates, whereas $x_{i}, y_{i}$, and $z_{i}$ are coordinates of nodes:

$$
\begin{gathered}
\{u\}=[N]\{q\} \\
\{u\}=\{u v w\} \\
\{u\}=\left\{u_{1} v_{1} w_{1} w_{2} w_{2} w_{2} \ldots\right\},
\end{gathered}
$$

where $u, v$, and $w$ are the displacements at points with local coordinates $\xi, \eta$, and $\zeta$, and $u_{i}, v_{i}$, and $w_{i}$ are displacement values at nodes.

Because FGMs are commonly used in the application where high temperature gradients are encountered, basic knowledge on the temperature distribution within the structure must be known. The first part of the present simulation is devoted to the phenomenon of thermal conduction, which shows the temperature flow from the higher temperature surface to the lower temperature surface. The relationship between the heat flux vector and the temperature distribution is explained by the Fourier law in the following expression:

$$
\{q\}=-[k] \nabla T,
$$

where $q$ is the heat flux vector, $T$ is the temperature, and $k$ is the thermal conductivity matrix. As the temperature decreases from the higher temperature surface to the lower temperature surface, the temperature variation is only available on the $z$ plane of the FG plate. The $x$ and $y$ planes show homogeneous temperature because there is no temperature change along these directions. The one-dimensional differential equation governed from the steady-state heat conduction of the FGM without heat source analysis performed in this study can be written as follows:

$$
\frac{\partial}{\partial z}\left(\gamma(z) \frac{\partial T}{\partial z}\right)=0
$$

The temperature gradient along the thickness direction of the FGM plate constructed from the thermal conductivity $k(z)$ values calculated based on the linear rule of mixtures is expressed as follows:

$$
T(z)=T_{U}-\frac{T_{U}-T_{L}}{\int_{-h / 2}^{h / 2}(d z / k(z))} \int_{z}^{h / 2} \frac{d \xi}{k(\xi)},
$$


where

$$
k(z)=k_{U}+\left(k_{L}-k_{U}\right)\left(\frac{z+(h / 2)}{h}\right)^{n},
$$

where $k_{U}$ and $k_{L}$ refer to the thermal conductivity of the upper and the lower surfaces of the plate, respectively. It should be noted that, in the case of homogeneous plates, the thermal conductivity does not depend on the thickness. This is why, in the pure metal and ceramic plates, there is only a similar temperature distribution that can be found.

It is obvious that the properties of each layer of the FGM must in some way represent an average of the properties of their individual components. The property averaging of the idealized model of the relatively isotropic nature of $\mathrm{HA} / \mathrm{Ti}$ FG plates can be illustrated by considering the modulus of elasticity of the composed materials. When the matrix of one of the composed materials is ultimately bonded to another material, the strain of both matrixes will be the same. This iso-strain condition is valid, although the elastic modulus of both materials will tend to be quite different. In other words,

$$
\epsilon_{\mathrm{fgm}}=\frac{\sigma_{\mathrm{fgm}}}{E_{\mathrm{fgm}}}=\epsilon_{c}=\frac{\sigma_{c}}{E_{c}}=\epsilon_{m}=\frac{\sigma_{m}}{E_{m}},
$$

where $\epsilon$ and $\sigma$ represent the strain and the stress, respectively, while $E$ is the Young modulus of the material. It is apparent that the load carried by the FG plate, $P_{\text {fgm }}$, is the simple sum of loads carried by each component:

$$
P_{\text {fgm }}=P_{c}+P_{m}
$$

where $P_{c}$ and $P_{m}$ refer to the load carried by ceramic and metal, respectively. Each load is equal, by definition, to a stress times cross-sectional area, which is

$$
\sigma_{\mathrm{fgm}} A_{\mathrm{fgm}}=\sigma_{c} A_{c}+\sigma_{m} A_{m} .
$$

$A_{\text {fgm }}$ is the area of the FGM plate, $A_{c}$ is the area of the ceramic, and $A_{m}$ is the area of the metal. Equally significant for the relative contribution of the ceramic phase to the FGM modulus is the fraction of the total FGM load, $P_{\mathrm{fgm}}$, in (13), carried by the axially loaded ceramic. Consider the following:

$$
\frac{P_{c}}{P_{\mathrm{fgm}}}=\frac{\sigma_{c} A_{c}}{\sigma_{\mathrm{fgm}} A_{\mathrm{fgm}}}=\frac{E_{c} v_{c}}{E_{\mathrm{fgm}}}
$$

where $v_{c}$ refers to the volume fraction of the ceramic phase. In most cases, higher modulus and strength of the ceramic are effectively transmitted to the FGM as a whole. As a result, the ductility of the matrix can produce a substantially less brittle material than the metal by itself. The concept of the thermomechanical analysis is based on the minimum potential energy principle, which states that

$$
\left[\left[K_{b}\right]+\left[K_{s}\right]\right]\left\{u^{0}\right\}=\left\{F_{T}\right\}+\{P\},
$$

where $\left[K_{s}\right]$ and $\left[K_{b}\right]$ are the element shear stiffness and bending matrices, respectively, while $\{P\}$ and $\left\{F_{T}\right\}$ are the element mechanical and thermal load vectors, respectively. Each of them can be defined by the following equations:

$$
\begin{gathered}
{\left[K_{s}\right]=\int_{A}\left[B_{s}\right]^{T}\left[D E_{s}\right]\left[B_{s}\right] d A,} \\
{\left[K_{b}\right]=\int_{A}\left[B_{b}\right]^{T}\left[D E_{b}\right]\left[B_{b}\right] d A,} \\
{[P]=\int_{A}\left[\psi_{i}^{e}\right]^{T}\{p\} d A,} \\
{\left[F_{T s}\right]=\int_{A}\left[B_{s}\right]^{T}\left\{D T_{s}\right\} d A,} \\
{\left[F_{T b}\right]=\int_{A}\left[B_{b}\right]^{T}\left\{D T_{b}\right\} d A .}
\end{gathered}
$$

From the equations, $\left[B_{s}\right]$ and $\left[B_{b}\right]$ refer to the curvature and shear strain displacement matrices, respectively. $E_{s}$ and $E_{b}$ are the shear and bending material Young modulus, $D$ is the material matrices, and $\{p\}$ is the mechanical load given on the element. The thermal load vectors, which are represented by $F_{T}$, are classified into two terms known as $F_{T s}$ and $F_{T b}$, which are considered within the element shear stiffness and bending, respectively. The definition of the normal stress $(\sigma)$ and strain $(\varepsilon)$ of the structure is based on the following equations:

$$
\begin{aligned}
& \left\{\sigma_{b}\right\}=\left[D_{b}\right]\left\{\varepsilon_{b}\right\}, \\
& \left\{\sigma_{s}\right\}=\left[D_{s}\right]\left\{\varepsilon_{s}\right\} .
\end{aligned}
$$

\section{Finite Element Modeling}

The numerical simulations of thermomechanical problems in FG plates are carried out by using the general-purpose finite element software package ANSYS. The simulations are divided into three parts, where the first part shows the temperature field calculation using a thermal analysis preference. The second part of the simulation demonstrates the structural analysis in which the displacement and the stress fields are calculated, while the last part combines both analyses to a thermal-structural coupled analysis to consider the thermomechanical problems in the FG structures. The typical thermal and mechanical properties of the FGM constituents used to define the material properties for the calculation are listed in Table 1 , where $k, E, v$, and $\alpha$ refer to thermal conductivity, Young modulus, Poisson ratio, and thermal expansion coefficient (CTE), respectively.

The model of the FG plate is designed to be in a 3D rectangular shape with eight overlapped layers. Because of the exponentially changed properties along the thickness of the FG plate, different properties calculated using the rule of mixture formulation are defined for each layer. However, because the effect of the variation of the Poisson ratio is negligible, this property is taken as a constant value upon which all the calculations are based on Apalak and Gunes [24]. The model is discretized into 400 elements and 3,003 nodes using a hexagonal mapped mesh function in mesh tool operation. The rectangular FG plate modeled throughout 
TABLE 1: Thermal and mechanical properties of pure HA and pure Ti used in the present calculations [25].

\begin{tabular}{lcccc}
\hline Material/properties & Elastic modulus, $E\left(\times 10^{9}\right) \mathrm{Pa}$ & Poisson ratio, $v$ & CTE, $\alpha\left(\times 10^{-6}\right) / \mathrm{K}$ & Thermal conductivity, $k \mathrm{~W} / \mathrm{mK}$ \\
\hline Titanium & $117^{*}$ & 0.34 & 10.9 & $17.5293^{*}$ \\
Hydroxyapatite & $73.1^{* *}$ & 0.28 & 14.87 & $2.16^{*}$ \\
\hline
\end{tabular}

${ }^{*}$ Moroi et al. [26], ${ }^{* *}$ Ruseska et al. [27].

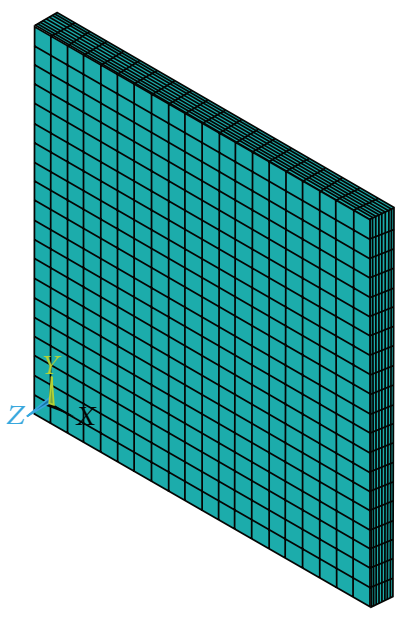

FIGURE 5: Geometry configuration of the FG plate model. Dimensions and geometry configuration: $U_{x}=U_{z}=0 ; U_{y}=U_{z}=0$; thickness, $h=0.01 \mathrm{~m}$; width, $a=0.2 \mathrm{~m}$; length, $b=0.2 \mathrm{~m}$; mesh count size $=20 \times 20$.

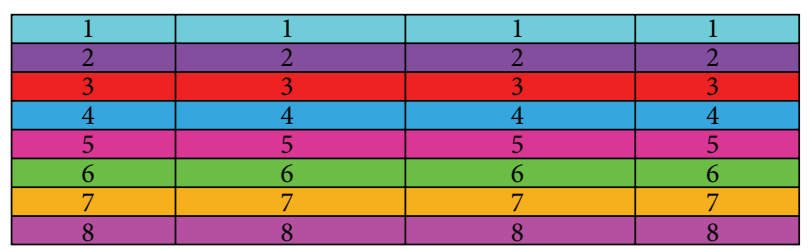

FIGURE 6: Properties' variation along the thickness of the FG plate model.

this FEM work is subjected to simply supported boundary condition where all nodes along $x$-direction edges are fixed in $x$ - and $z$-directions and all nodes along the $y$-direction edges are fixed in $y$ - and $z$-directions. Figures 5 and 6 display the geometric configuration and the property definition of the FG plate model, respectively.

From Figure 6, the bottom (material number 1) and the top layers (material number 8 ) have the pure ceramic and metal properties, respectively, whereas the intermediate layers (material numbers 2 to 7 ) possess the gradually changed material properties from the different stepwise compositions of both the ceramic and the metal materials. Considering the real service condition where the ceramic phase is typically taken as a thermal barrier on the metal-based structural components in various heat-resistant coatings, the top and the bottom surfaces of the FG plate are assigned to be ceramic- and metal-rich layers, respectively. The concept of the thermomechanical analysis can be understood clearly using the illustration given in Figure 7.

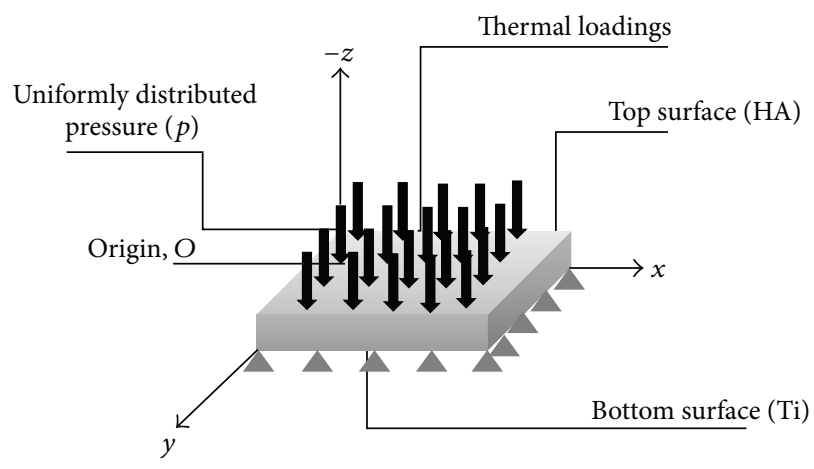

FIgURE 7: Thermomechanical analysis of HA/Ti FG plate.

It is indicated that, for the thermomechanical problem simulation, the FG plate is subjected to either a constant or a functional mechanical transverse load on the ceramic-rich top surface in addition to a thermal load where the higher temperature is located at the top surface, whereas the lower temperature is located at the bottom.

For the simulation of the temperature field, the thermal conductivity of the plate can be input directly in the material model as thermal parameter. For constant loading, the high temperature of $300^{\circ} \mathrm{C}$ is loaded at the top surface of the FG plate as a thermal load while the bottom surface is maintained at $20^{\circ} \mathrm{C}$ of room temperature. The functional parameter of the sinusoidal thermal loading is defined as follows:

$$
T^{+}=T \sin \left(\frac{\pi x}{a}\right) \sin \left(\frac{\pi y}{b}\right)
$$

where $T$ is completing as $300^{\circ} \mathrm{C}, x$ is the coordinate at the $x$-plane, and $y$ is the coordinate at the $y$-plane. After finishing the simulation of the temperature field, the element is switched to its corresponding structural element in order to get the structural response of the FGMs. The elastic modulus, Poisson ratio, and the coefficient of thermal expansion are input directly in the material model as structural parameters. The steady-state simulation results of the temperature field are used in the structural response analyses as the thermal loads. The pressure load is applied to the top surface of the FG plate as a mechanical surface load. The function of the sinusoidal mechanical loading is defined as follows:

$$
p^{+}=p \sin \left(\frac{\pi x}{a}\right) \sin \left(\frac{\pi y}{b}\right)
$$

where $p$ is the load intensity given to the FG plate. 
TABLE 2: Convergence study of simply supported $\mathrm{Ni} / \mathrm{ZrO}_{2}$ FG plates subjected to thermal loadings with respect to different mesh divisions.

\begin{tabular}{lccccccc}
\hline Parameter & $z / h$ & Established [28] & $8 \times 8$ & $16 \times 16$ & $20 \times 20$ & $50 \times 50$ & $55 \times 55$ \\
\hline Temperature $(T)$ & 0.5 & 0.2432 & 0.2778 & 0.2779 & 0.2779 & 0.2779 & 0.2779 \\
\hline \multirow{2}{*}{ In-plane displacement $\left(u_{x}\right)$} & 0 & 0.08492 & 0.0432 & 0.0432 & 0.0432 & 0.0432 & 0.0432 \\
& 0.5 & -0.7862 & -0.6887 & -0.6889 & -0.6889 & -0.6889 & -0.6889 \\
& 1 & -1.699 & -1.456 & -1.456 & -1.456 & -1.456 & -1.456 \\
Transverse displacement $\left(u_{z}\right)$ & 0 & 5.522 & 4.632 & 4.634 & 4.634 & 4.634 & 4.634 \\
& 1 & 5.635 & 4.738 & 4.739 & 4.739 & 4.739 & 4.739 \\
& 0 & 6.021 & 5.070 & 5.071 & 5.071 & 5.071 & 5.071 \\
\hline \multirow{2}{*}{ Normal stress $\left(\sigma_{x x}\right)$} & 0.5 & -75.78 & -49.53 & -48.58 & -48.47 & -48.30 & -48.26 \\
& 1 & -1006 & -293.7 & -321.1 & -320.3 & -319.2 & -318.9 \\
\hline Transverse stress $\left(\sigma_{z z}\right)$ & 0.5 & 1.015 & 0.8590 & 0.8454 & 0.8381 & 0.8318 & 0.8309 \\
\hline Transverse shear stress $\left(\tau_{x z}\right)$ & 0.5 & 1.583 & 2.239 & 2.237 & 2.231 & 2.224 \\
\hline
\end{tabular}

TABLE 3: Convergence study of simply supported $\mathrm{Ni} / \mathrm{ZrO}_{2}$ FG plates subjected to thermal loadings with respect to different layer numbers.

\begin{tabular}{|c|c|c|c|c|c|}
\hline Parameter & $z / h$ & Established [28] & 6 Layers & 8 Layers & 9 Layers \\
\hline Temperature $(T)$ & 0.5 & 0.2432 & 0.2844 & 0.2779 & 0.2769 \\
\hline \multirow{3}{*}{ In-plane displacement $\left(u_{x}\right)$} & 0 & 0.08492 & 0.0479 & 0.0432 & 0.0400 \\
\hline & 0.5 & -0.7862 & -0.7106 & -0.6889 & -0.6822 \\
\hline & 1 & -1.699 & -1.506 & -1.456 & -1.439 \\
\hline \multirow{3}{*}{ Transverse displacement $\left(u_{z}\right)$} & 0 & 5.522 & 4.801 & 4.634 & 4.51 \\
\hline & 0.5 & 5.635 & 4.91 & 4.739 & 4.674 \\
\hline & 1 & 6.021 & 5.252 & 5.071 & 5.003 \\
\hline \multirow{3}{*}{ Normal stress $\left(\sigma_{x x}\right)$} & 0 & -75.78 & -53.49 & -48.26 & -44.71 \\
\hline & 0.5 & -243 & -331.2 & -318.9 & -304.4 \\
\hline & 1 & -1006 & -1106 & -1093 & -1078 \\
\hline Transverse stress $\left(\sigma_{z z}\right)$ & 0.5 & 1.015 & 0.9179 & 0.8309 & 0.7588 \\
\hline Transverse shear stress $\left(\tau_{x z}\right)$ & 0.5 & 1.583 & 2.497 & 2.222 & 1.927 \\
\hline
\end{tabular}

\section{Results and Discussion}

Numerical results are presented in this section for simply supported HA/Ti FG rectangular plates with various grading indices. The FEM calculations have been performed by taking into consideration the loading parameters from thermal, mechanical, and coupled thermomechanical loads to observe the effects of different loading conditions on the response of the FG plates. In order to ensure that the requirements for the simulation model have been transferred to the computer model with sufficient accuracy, the first part of this section shows the verification of the FEM calculations through the comparison between the present results and the established research results. The results on the temperature, the displacement, and the stress fields of HA/Ti FG plates subjected to thermal, mechanical, and thermomechanical loadings are given and discussed deeply in the subsequent sections with the intention of using the FGM in thermal barrier applications.

4.1. Modeling Verification. Verification of the FEM model is addressed through three steps. In the early stage of the verification process, the reliability of the steady-state thermal analysis method is confirmed because the present values of temperature distributions in $\mathrm{Al} / \mathrm{ZrO}_{2}$ shown in Figure 8 are highly consistent with those presented in Alshorbagy et al. [29]. It is indicated from the thermal analysis that the homogeneous plates' thermal profiles exhibited higher temperature distribution than those that belong to the FG plates. The dependence of the temperature field on the thermal profile at the surfaces and the corresponding thermal conductivity properties of the constituents exhibit that the grading parameter $n$ has a dominant role on the thermal characteristic of the FG plates.

The result of the thermal analysis is defined as the thermal loads for thermal-structural coupled analysis in which the calculation of thermal stress is performed. The convergence studies of simply supported Monel/Zirconia FG plates subjected to thermal loads with respect to various mesh and layer numbers are summarized in Tables 2 and 3, respectively. The results in Table 2 indicate that as the mesh division increases, the FG plates' response properties' values converge at the established research results. Table 2 indicates that the increased layer number leads to better thermal stress relaxation because of the smaller mismatch in material properties of the constituents. The results from the present calculation 
TABLE 4: Nondimensional central deflection of $\mathrm{Al} / \mathrm{ZrO}_{2}$ FG plates subjected to mechanical loadings.

\begin{tabular}{|c|c|c|c|c|c|c|c|c|c|c|}
\hline \multicolumn{11}{|c|}{ Nondimensional central deflection $(\bar{\omega})$} \\
\hline \multirow{2}{*}{$\bar{P}$} & \multicolumn{2}{|r|}{ Metal } & \multicolumn{2}{|r|}{$n=0.5$} & \multicolumn{2}{|r|}{$n=1$} & \multicolumn{2}{|r|}{$n=2$} & \multicolumn{2}{|r|}{ Ceramic } \\
\hline & Present & Established [20] & Present & Established [29] & Present & Established [29] & Present & Established [29] & Present & Established [29] \\
\hline 1 & 0.0449 & 0.0452 & 0.0264 & 0.0317 & 0.0297 & 0.0287 & 0.0326 & 0.0267 & 0.0208 & 0.0210 \\
\hline 2 & 0.0897 & 0.0905 & 0.0528 & 0.0633 & 0.0594 & 0.0573 & 0.0652 & 0.0534 & 0.0416 & 0.0420 \\
\hline 3 & 0.1346 & 0.1357 & 0.0792 & 0.0950 & 0.0891 & 0.0860 & 0.0978 & 0.0801 & 0.0623 & 0.0629 \\
\hline 4 & 0.1794 & 0.1810 & 0.1056 & 0.1266 & 0.1192 & 0.1146 & 0.1304 & 0.1067 & 0.0832 & 0.0839 \\
\hline 5 & 0.2243 & 0.2262 & 0.1320 & 0.1583 & 0.1486 & 0.1433 & 0.1631 & 0.1334 & 0.1040 & 0.1049 \\
\hline 6 & 0.2692 & 0.2714 & 0.1584 & 0.1899 & 0.1782 & 0.1720 & 0.1957 & 0.1601 & 0.1248 & 0.1258 \\
\hline 7 & 0.3140 & 0.3167 & 0.1848 & 0.2216 & 0.2080 & 0.2006 & 0.2283 & 0.1868 & 0.1456 & 0.1468 \\
\hline 8 & 0.3589 & 0.3619 & 0.2112 & 0.2532 & 0.2377 & 0.2293 & 0.2609 & 0.2135 & 0.1664 & 0.1678 \\
\hline 9 & 0.4038 & 0.4072 & 0.2376 & 0.2849 & 0.2674 & 0.2579 & 0.2935 & 0.2402 & 0.1872 & 0.1888 \\
\hline 10 & 0.4486 & 0.4524 & 0.2640 & 0.3166 & 0.2971 & 0.2899 & 0.3261 & 0.2669 & 0.2080 & 0.2097 \\
\hline 11 & 0.4935 & 0.4979 & 0.2903 & 0.3482 & 0.3269 & 0.3153 & 0.3587 & 0.2935 & 0.2288 & 0.2307 \\
\hline 12 & 0.5384 & 0.5428 & 0.3167 & 0.3799 & 0.3566 & 0.3439 & 0.3913 & 0.3202 & 0.2496 & 0.2517 \\
\hline
\end{tabular}

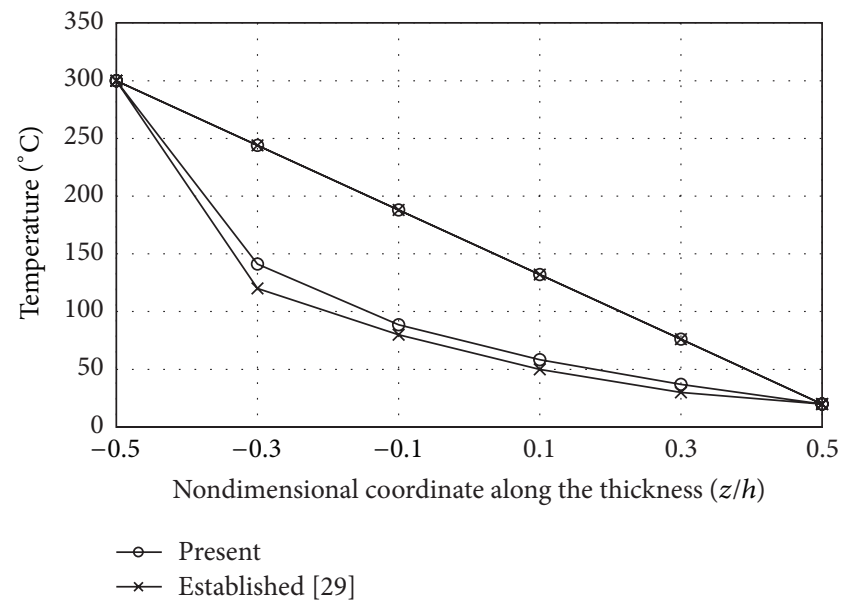

FIGURE 8: Temperature field distribution along the thickness of FG plates.

are in excellent agreement with those reported in Srinivas et al. [30] and Reddy and Cheng [28].

The deflections of the $\mathrm{Ni} / \mathrm{ZrO}_{2}$ FG plates subjected to mechanical loads calculated in the present simulation are shown in Table 4. The displacement and the stress field results are obtained using structural analysis that considers the typical properties such as the elastic modulus, the CTE, and the Poisson ratio. The simulation method is verified because the present values are highly consistent with that reported in Alshorbagy et al. [29].

The thermal-structural coupled model that was developed in order to calculate the thermoelastic behaviors of the FG plates subjected to thermomechanical loadings is verified in this section because the present results are in excellent agreement with those presented in Alshorbagy et al. [29], which are shown in Table 5. In response to the simulation method verification, the FEM formulation used in this study is considered valid for determining the solutions for thermomechanical problems in FGMs.
4.2. Thermoelastic Properties of HA/Ti FGM. The FEM simulation verified in the previous section is used for the analysis of thermomechanical problems in HA/Ti FG plates with various grading indices, $n$. The results of the temperature profile, the displacement, and the stress distribution of $\mathrm{HA} / \mathrm{Ti}$ FG plates imposed to thermal, mechanical, and coupled thermomechanical loadings simulated from the present FE analysis are given and discussed in this section. The structural responses of the FG plates are given in terms of the following nondimensional parameters:

$$
\begin{aligned}
& \text { nondimensional load intensity, } \bar{P}=a^{2} p / E_{b} h^{4}, \\
& \text { nondimensional normal stress, } \sigma_{x x}^{-}=\sigma_{x x}\left(h^{2} / a^{2} p\right), \\
& \text { nondimensional transverse shear stress, } \tau_{x z}^{-}=\tau_{x z}\left(h^{2} /\right. \\
& \left.a^{2} p\right) \text {, } \\
& \text { nondimensional central deflection, } \bar{\omega}=\omega / h, \\
& \text { nondimensional thickness, } \bar{h}=h \times 10^{2}, \\
& \text { nondimensional coordinate at } x \text {-direction, } \bar{a}=a \times \\
& 10^{1},
\end{aligned}
$$

where $p, a, h$, and $E_{b}$ are referring to the pressure load, plate length, plate thickness, and Young modulus of the bottom surface material, respectively.

4.2.1. Deformation by Thermal Loadings. In the steady-state heat conduction analysis, the HA/Ti FG plate is subjected to a temperature gradient along the thickness where the temperature of the HA top surface is $300^{\circ} \mathrm{C}$ and the temperature of the Ti bottom surface is $20^{\circ} \mathrm{C}$. Figure 9 depicts the temperature distribution profile achieved from the FE simulation for the $\mathrm{HA} / \mathrm{Ti}$ FG plates. It shows the temperature contour for heat conduction from the higher temperature $300^{\circ} \mathrm{C}$ surfaces to the lower temperature $20^{\circ} \mathrm{C}$ surfaces in FG plates with various grading indices $(n=0,1,2, \infty)$. From the analysis, it is observed that the temperature distribution within the homogeneous plates $(n=0, \infty)$ is usually larger than those of FG plates $(n=1,2)$. The dependence of the temperature profile on the thermal conductivity of the constituents' mismatch, 
TAble 5: Nondimensional deflection at the central point of $\mathrm{Al} / \mathrm{ZrO}_{2} \mathrm{FG}$ plates subjected to coupled thermomechanical loadings.

\begin{tabular}{|c|c|c|c|c|c|c|c|c|}
\hline \multirow{3}{*}{$\bar{P}$} & \multicolumn{8}{|c|}{ Nondimensional central deflection $(\bar{\omega})$} \\
\hline & \multicolumn{2}{|r|}{ Metal } & \multicolumn{2}{|c|}{$n=1$} & \multicolumn{2}{|r|}{$n=2$} & \multicolumn{2}{|c|}{ Ceramic } \\
\hline & Present & Established [29] & Present & Established [29] & Present & Established [29] & Present & Established [29] \\
\hline 1 & -0.2015 & -0.2050 & -0.0527 & -0.0665 & -0.0580 & -0.0547 & -0.0863 & -0.0879 \\
\hline 2 & -0.1567 & -0.1598 & -0.0230 & -0.0379 & -0.0254 & -0.0280 & -0.0656 & -0.0669 \\
\hline 3 & -0.1119 & -0.1146 & 0.0067 & -0.0092 & 0.0072 & -0.0013 & -0.0448 & -0.0459 \\
\hline 4 & -0.0671 & -0.0690 & 0.0364 & 0.0195 & 0.0398 & 0.0254 & -0.0241 & -0.0250 \\
\hline 5 & -0.0223 & -0.0240 & 0.0661 & 0.0481 & 0.0724 & 0.0521 & -0.0033 & -0.0040 \\
\hline 6 & 0.0225 & 0.0210 & 0.0958 & 0.0768 & 0.1050 & 0.0788 & 0.0175 & 0.0170 \\
\hline 7 & 0.0667 & 0.0660 & 0.1255 & 0.1054 & 0.1376 & 0.1054 & 0.0383 & 0.0380 \\
\hline 8 & 0.1120 & 0.1115 & 0.1552 & 0.1341 & 0.1702 & 0.1321 & 0.0590 & 0.0589 \\
\hline 9 & 0.1568 & 0.1568 & 0.1849 & 0.1628 & 0.2028 & 0.1588 & 0.0798 & 0.0799 \\
\hline 10 & 0.2016 & 0.2020 & 0.2146 & 0.1914 & 0.2354 & 0.1855 & 0.1005 & 0.1009 \\
\hline 11 & 0.2464 & 0.2473 & 0.2443 & 0.2201 & 0.2680 & 0.2122 & 0.1213 & 0.1219 \\
\hline 12 & 0.2912 & 0.2925 & 0.2741 & 0.2487 & 0.3006 & 0.2389 & 0.1421 & 0.1428 \\
\hline
\end{tabular}

which thus affects the thermal loading, shows the domination of the grading parameter $n$ on the thermal field of the HA/Ti FG plates. A comparison between the temperature profile of FG plates subjected to constant loading and that subjected to functional loading shows no significant difference as shown in Figure 10.

The grading number, $n=1$, is taken as the optimum grading index for HA/Ti FG plates because it leads to the maximum thermal relaxation with the lowest temperature distribution within the FG plate. The temperature profile obtained from the thermal analysis is transferred to the structural analysis as the thermal loading. The deflection of the HA/Ti FG plates with various grading indices under thermal excitation is shown in Figure 11.

It is indicated that the deflection in FG plates is in intermediate layers between the full ceramic and the full metal plates. The elongation of the FG plates subjected to thermal loading depends on the CTE properties. In this study, it is known that the CTE of HA is higher than that of Ti. As the volume fraction of the ceramic phase increases within the smaller grading index number, the properties of the ceramic will dominate the deformation behavior of the FG plates. The results shown in Figure 11 are in excellent agreement with the theory and thus lead to the conclusion that the grading parameter $n$ has a dominant effect on the structural response of the HA/Ti FG plates subjected to thermal loading.

The normal stress field distribution in HA/Ti FG plates induced by the temperature profile shown in Figures 10 and 11 is shown in Figure 12. The smaller area of maximum normal stress contours for FG plates $(n=1,2)$ illustrated in Figure 12 is very advantageous to show the thermal stress relaxation in FGMs. The similar normal stress contour distribution of full ceramic and full metal plates $(n=0, \infty)$ shows that the variation of thermal conductivity is negligible for homogeneous plates with heat conduction calculation. The nondimensional normal stress distribution along the thickness of HA/Ti FG plates subjected to thermal loading is given in Figure 13. The maximum tensile stress is located at the Ti bottom surface, while the maximum compressive stress appears at the HA top surface of the FG plates. Both stress components are lower than that of homogeneous plates. The results reveal that grading parameter, $n$, does affect the response of FG plates under thermal loadings.

Figure 14 depicts the transverse shear stress field distribution in HA/Ti FG plates with various grading parameters under thermal loadings. The different shear stress contours between homogeneous and FG plates lead to the conclusion that the properties' gradation in FGMs has impressed on the transverse shear stress response of FGMs subjected to thermal loading. The nondimensional transverse shear stress distribution in the middle plane for various grading parameters of HA/Ti FG plates is indicated in Figure 15.

The shear stress field is significant for the area near the edges of the FG plates because there are shear stress fields observed at this location. The shear stress at the locations away from the surface of the FG plates is similar for various grading parameters, $n$. The difference between the shear stress field distribution of homogeneous and FG plates displayed in Figure 15 shows that the grading parameter $n$ does affect the shear stress response of the FG plates under thermal loads.

4.2.2. Deformation by Mechanical Loadings. In order to calculate the elastostatic behavior of the FG plates with various grading indices, the pressure load that takes place in the interval of $\{1,12\}$ is applied to the HA top surface. The structural responses of FG plates subjected to mechanical loads will be shown and discussed in this section. To study the displacement response, the nondimensional central deflection of HA/Ti FG plates with various grading parameters, $n$, subjected to mechanical loadings summarized in Table 6 can be considered.

It is noticed that the nondimensional deflection of FG plates subjected to constant loadings is higher than those subjected to sinusoidal loadings. When subjected to constant loadings, the whole area at the same plane of the plate is imposed to a uniformly distributed load. However, when imposed on sinusoidal loadings, a certain coordinate is imposed on a certain loading magnitude. As a result, 


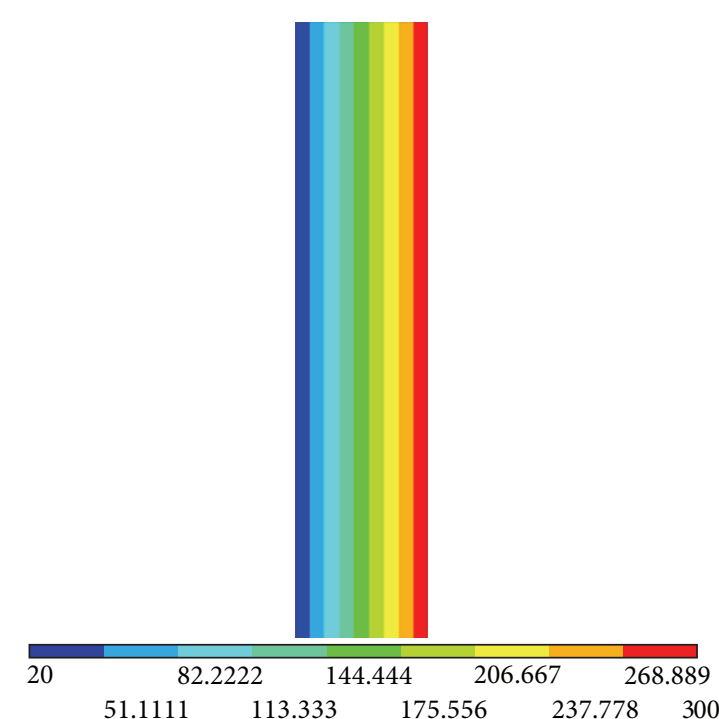

(a) $n=0$

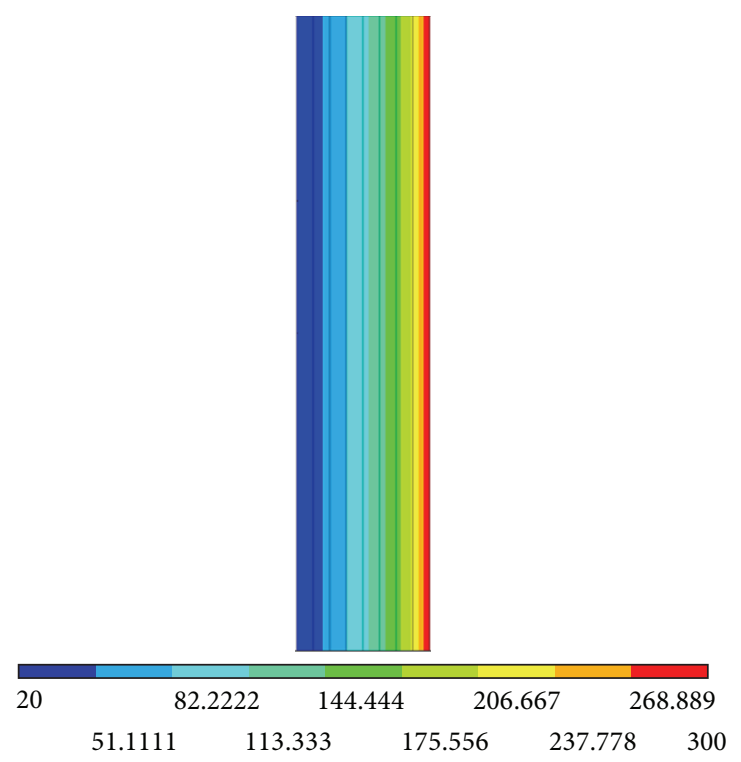

(c) $n=2$

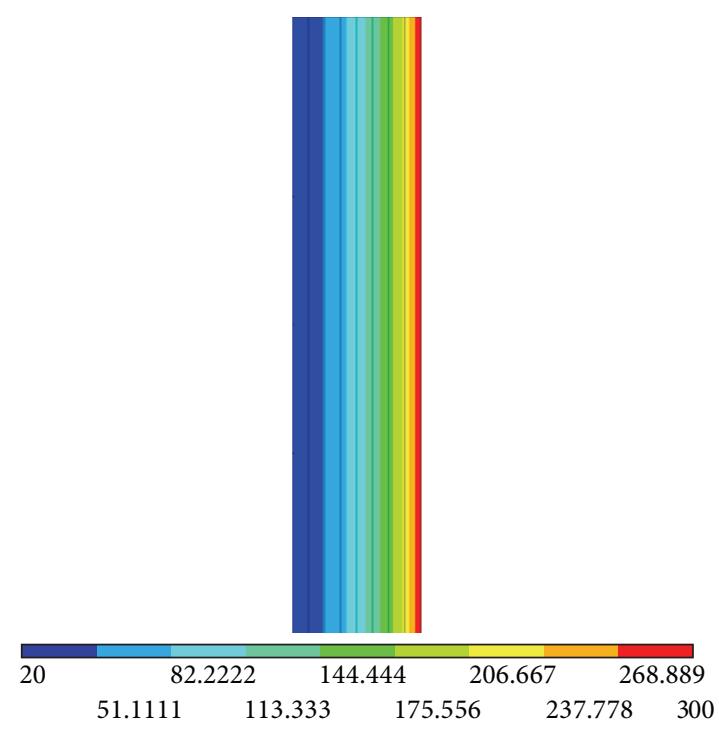

(b) $n=1$

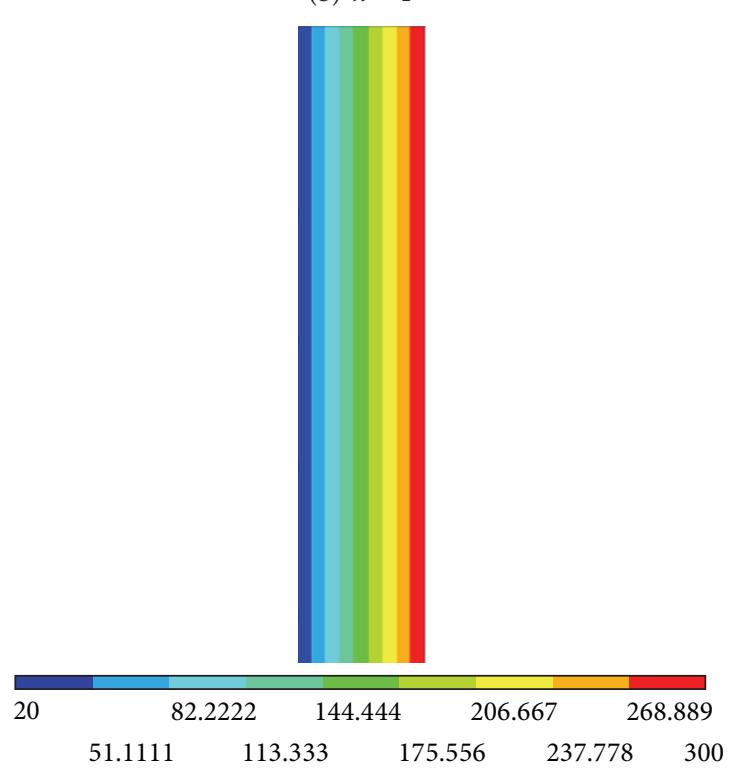

(d) $n=\infty$

FIGURE 9: Temperature profile along the $z$-direction of HA/Ti FG plates under thermal loadings.

the lower deflection is obtained in FG plates subjected to functional loadings. Figure 16 depicts the nondimensional central deflections of the FG plates with various grading parameters induced by the different load intensities.

It can be seen that the central deflection, $\bar{\omega}$, decreases with the increase in the grading index number, $n$. It is known that the displacement response of a material strongly depends on the elastic moduli of its ingredient. The FG plates with a higher grading index number contain higher ceramic volume fractions. Because the elastic moduli of the HA are lower than that of the $\mathrm{Ti}$, the high toughness property of the metal dominates the elastic properties of the FG plates. The rigidity of FG plates with higher Ti volume fraction will be higher as well. The property averaging of the relatively isotropic nature of HA/Ti FG plates leads to the intermediate deflection between the full ceramic and full metal deflection given in Figure 16.

The normal stress field in HA/Ti FG plates with various grading parameters $n$ is illustrated in Figure 17. The normal stress induced by mechanical loadings is not significant because there is no variation in the stress contours. However, the differences in normal stress values of homogeneous and FG plates are advantageous to explain the domination of the grading parameter $n$.

4.2.3. Deformation by Thermomechanical Loading. In this section, the thermomechanical problem with HA/Ti FG plates with various grading parameters, $n$, is considered. 


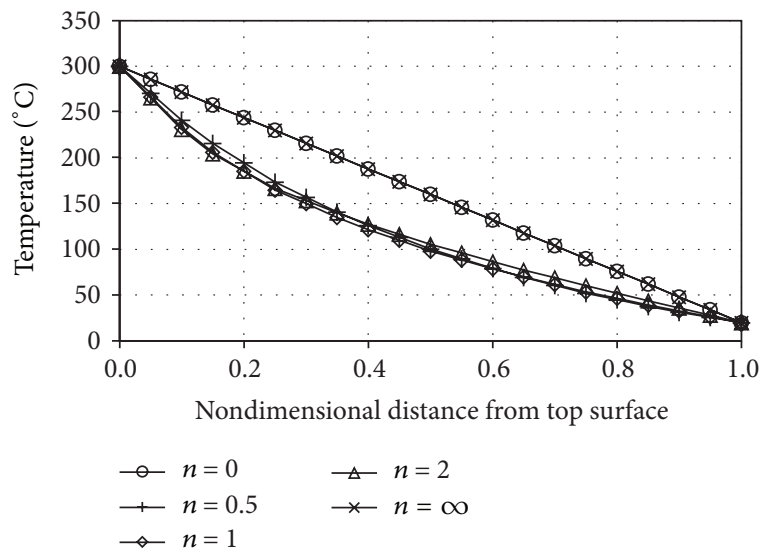

(a) Constant loadings

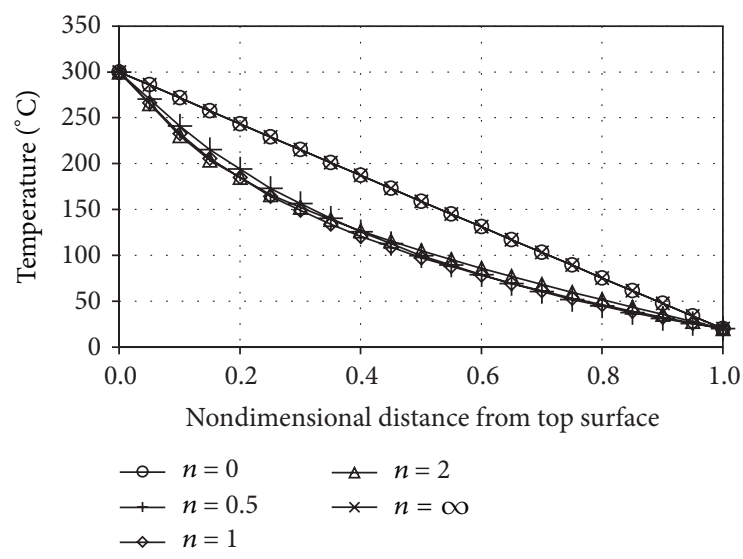

(b) Sinusoidal loadings

FIGURE 10: Temperature field distribution along $z$-direction of the HA/Ti FG plates under thermal loadings.

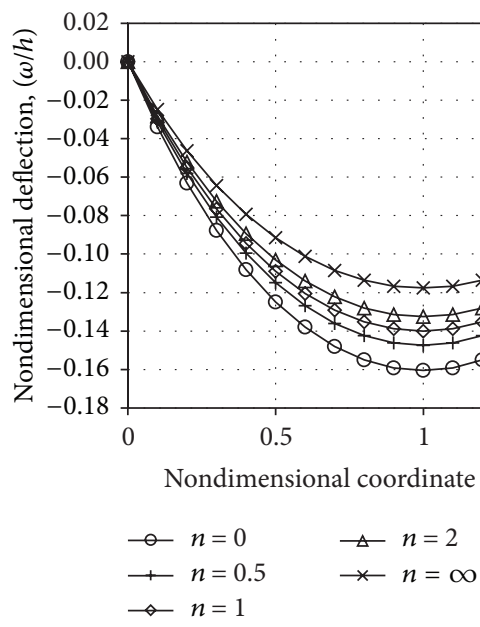

(a) Constant loadings

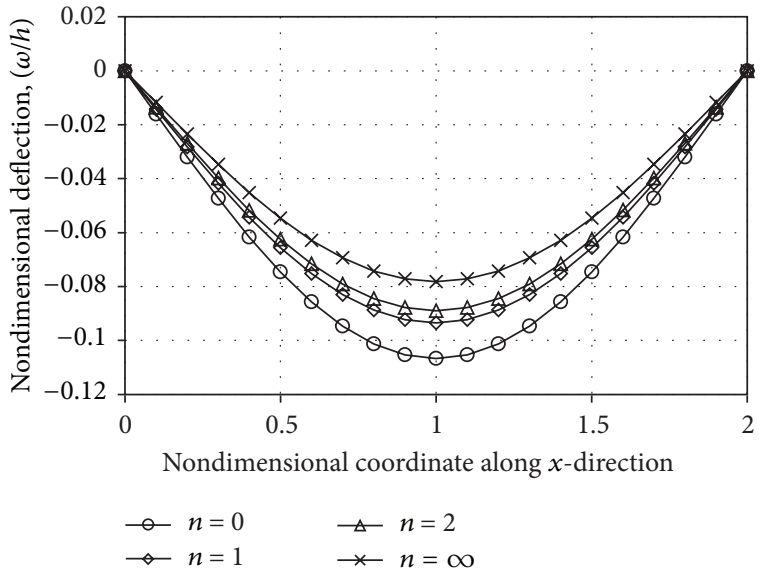

(b) Sinusoidal loadings

FIGURE 11: Nondimensional deflection of HA/Ti FG plates under thermal loadings.

TABLE 6: Nondimensional central deflection of HA/Ti FG plates versus nondimensional load intensity (without thermal loadings).

\begin{tabular}{|c|c|c|c|c|c|c|c|c|c|c|}
\hline \multirow{3}{*}{$\bar{P}$} & \multicolumn{10}{|c|}{ Nondimensional central deflection $\bar{\omega}$} \\
\hline & \multicolumn{2}{|c|}{ HA } & \multicolumn{2}{|c|}{$n=0.5$} & \multicolumn{2}{|c|}{$n=1$} & \multicolumn{2}{|c|}{$n=2$} & \multicolumn{2}{|c|}{$\mathrm{Ti}$} \\
\hline & Constant & Functional & Constant & Functional & Constant & Functional & Constant & Functional & Constant & Functional \\
\hline 1 & 0.0712 & 0.0449 & 0.0593 & 0.0373 & 0.0558 & 0.0352 & 0.0530 & 0.0334 & 0.0445 & 0.0280 \\
\hline 2 & 0.1424 & 0.0897 & 0.1186 & 0.0747 & 0.1115 & 0.0703 & 0.1060 & 0.0668 & 0.0890 & 0.0561 \\
\hline 3 & 0.2137 & 0.1345 & 0.1779 & 0.1120 & 0.1673 & 0.1054 & 0.1591 & 0.1002 & 0.1335 & 0.0841 \\
\hline 4 & 0.2849 & 0.1794 & 0.2372 & 0.1493 & 0.2231 & 0.1405 & 0.2121 & 0.1336 & 0.1780 & 0.1121 \\
\hline 5 & 0.3561 & 0.2242 & 0.2965 & 0.1867 & 0.2789 & 0.1756 & 0.2652 & 0.1670 & 0.2225 & 0.1401 \\
\hline 6 & 0.4274 & 0.2691 & 0.3558 & 0.2240 & 0.3347 & 0.2108 & 0.3182 & 0.2004 & 0.2670 & 0.1681 \\
\hline 7 & 0.4986 & 0.3193 & 0.4157 & 0.2614 & 0.3905 & 0.2459 & 0.3713 & 0.2338 & 0.3115 & 0.1961 \\
\hline 8 & 0.5699 & 0.3588 & 0.4744 & 0.2987 & 0.4467 & 0.2810 & 0.4243 & 0.2672 & 0.3560 & 0.2242 \\
\hline 9 & 0.6411 & 0.4037 & 0.5337 & 0.3361 & 0.5021 & 0.3162 & 0.4774 & 0.3006 & 0.4005 & 0.2522 \\
\hline 10 & 0.7123 & 0.4485 & 0.5930 & 0.3734 & 0.5579 & 0.3513 & 0.5304 & 0.3340 & 0.4450 & 0.2802 \\
\hline 11 & 0.7836 & 0.4934 & 0.6523 & 0.4107 & 0.6137 & 0.3864 & 0.5855 & 0.3674 & 0.4895 & 0.3082 \\
\hline 12 & 0.8548 & 0.5382 & 0.7116 & 0.4481 & 0.6695 & 0.4216 & 0.6365 & 0.4008 & 0.5341 & 0.3363 \\
\hline
\end{tabular}




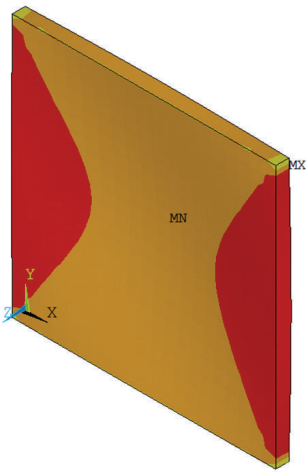

$\begin{array}{cccccc}-0.163 E+09 & -0.125 E+09 & -0.858 E+08 & -0.470 E+08 & -0.818 E+07 \\ -0.144 E+09 & -0.105 E+09 & -0.664 E+08 & -0.276 E+08 & 0.112 E+08\end{array}$

(a) $n=0$

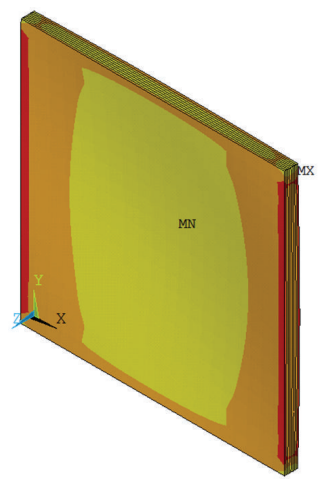

$-0.249 E+09 \quad-0.186 E+09 \quad-0.122 E+09 \quad-0.581 E+08 \quad 0.560 E+07$

$-0.217 E+09 \quad-0.154 E+09 \quad-0.900 E+08 \quad-0.263 E+08 \quad 0.375 E+08$

(c) $n=2$
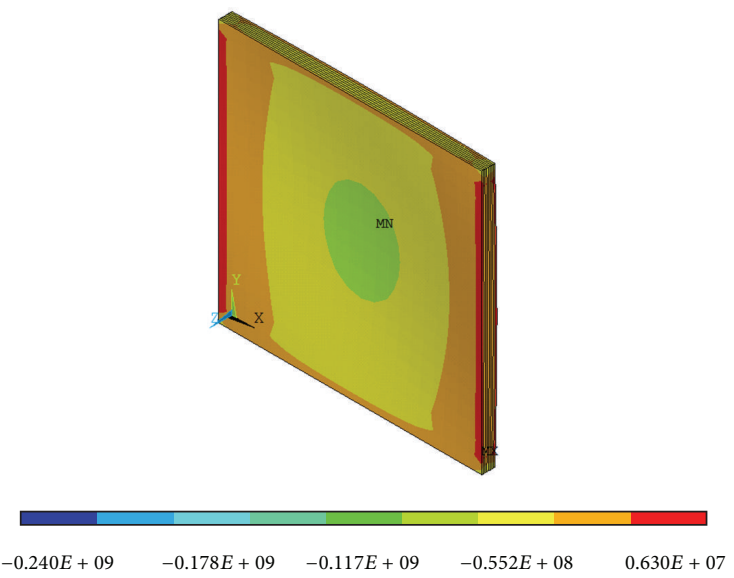

$\begin{array}{lllll}-0.209 E+09 & -0.148 E+09 & -0.860 E+08 & -0.245 E+08 & 0.371 E+08\end{array}$

(b) $n=1$

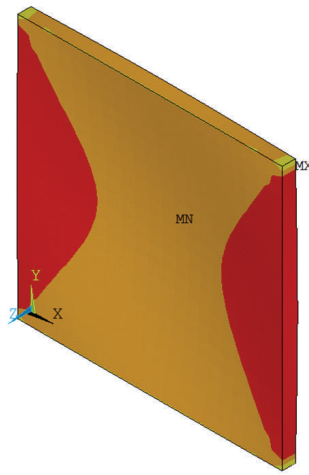

$-0.192 E+09 \quad-0.146 E+09 \quad-0.101 E+09 \quad-0.551 E+08 \quad-0.960 E+07$

$$
-0.169 E+09 \quad-0.123 E+09 \quad-0.779 E+08 \quad-0.324 E+08 \quad 0.132 E+08
$$

(d) $n=\infty$

FIGURE 12: Normal stress field distribution of HA/Ti FG plates under thermal loadings.

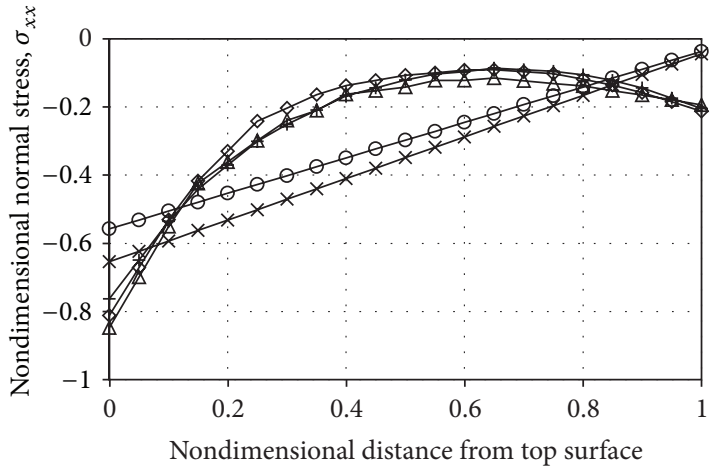

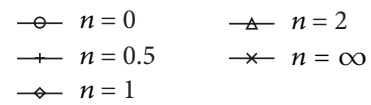

(a) Constant loadings

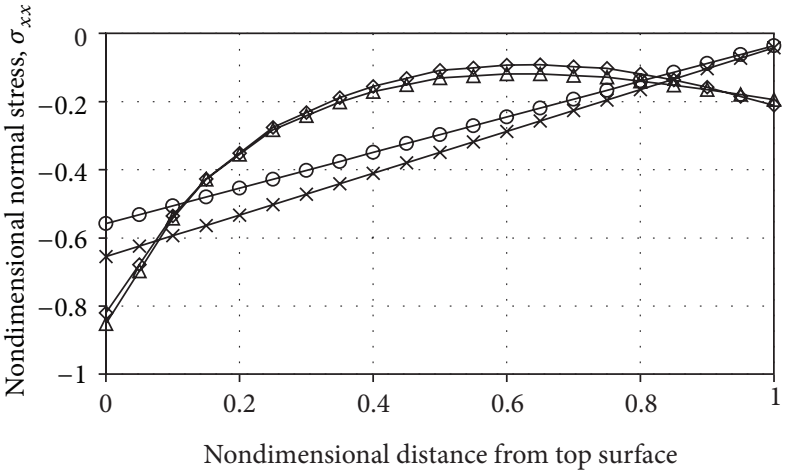

$\rightarrow n=0 \quad \triangle n=2$

$\multimap n=1 \quad * n=\infty$

(b) Sinusoidal loadings

FIGURE 13: Nondimensional normal stress distribution along the $z$-direction of HA/Ti FG plates under thermal loadings. 

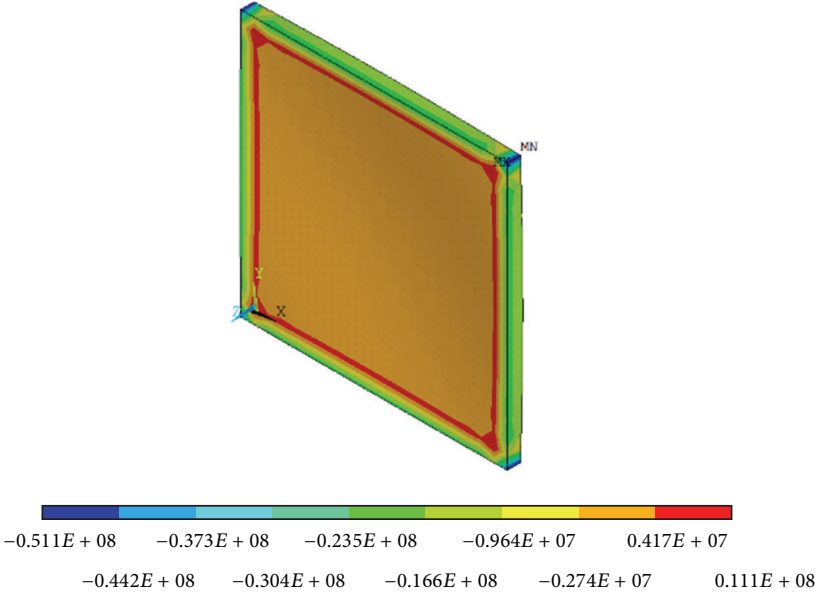

(a) $n=0$

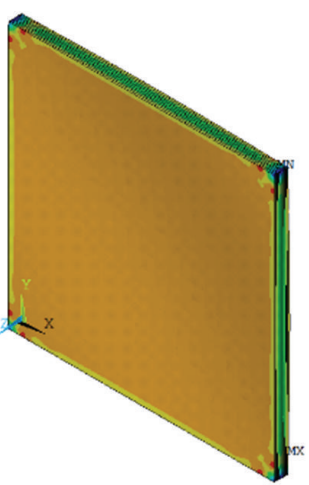

$-0.589 E+08 \quad-0.428 E+08 \quad-0.267 E+08 \quad-0.106 E+08 \quad 0.548 E+07$

$-0.508 E+08 \quad-0.347 E+08 \quad-0.187 E+08 \quad-0.256 E+07 \quad 0.135 E+08$

(c) $n=2$

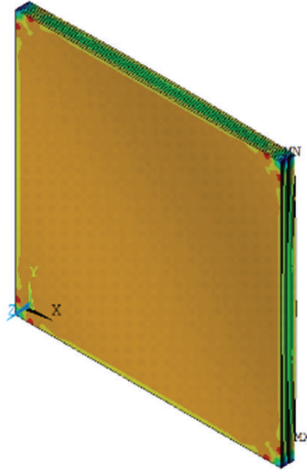

$-0.584 E+08 \quad-0.425 E+08 \quad-0.267 E+08 \quad-0.108 E+08 \quad 0.504 E+07$ $-0.505 E+08 \quad-0.346 E+08 \quad-0.187 E+08 \quad-0.288 E+07$ $0.130 E+08$ (b) $n=1$
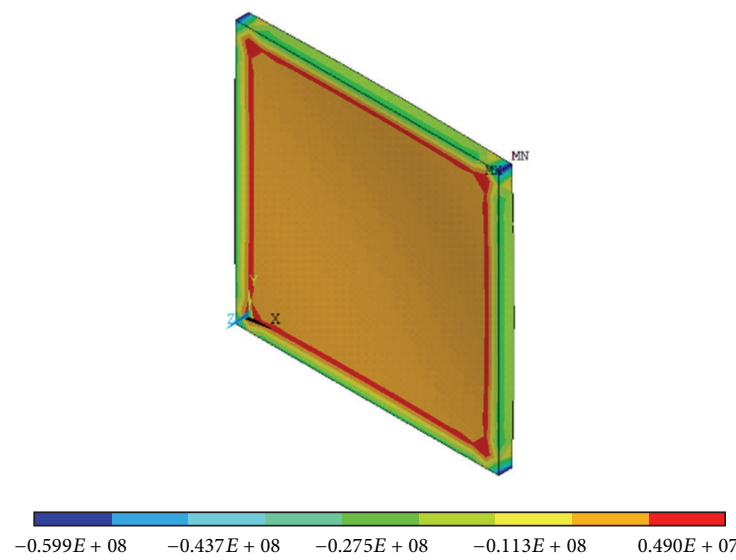

$-0.518 E+08 \quad-0.356 E+08 \quad-0.194 E+08$

(d) $n=\infty$

FIgURE 14: Transverse shear stress field distribution of HA/Ti FG plates under thermal loadings.

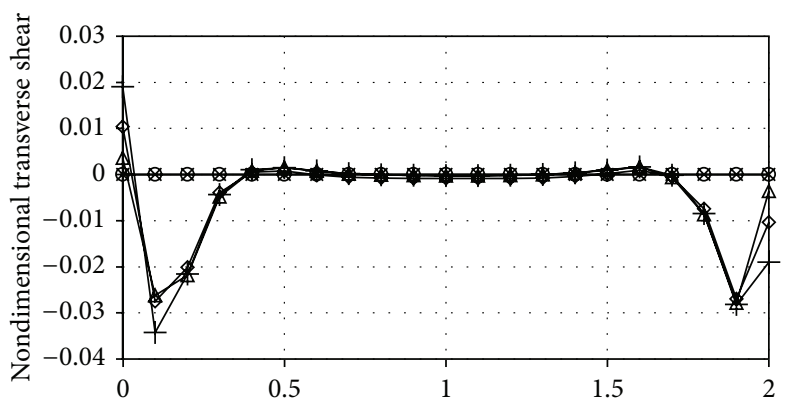

Nondimensional coordinate along $x$-direction

$$
\begin{array}{ll}
\multimap n=0 & \triangle n=2 \\
\rightarrow n=0.5 & \quad * n=\infty \\
\rightarrow n=1 &
\end{array}
$$

(a) Constant loadings

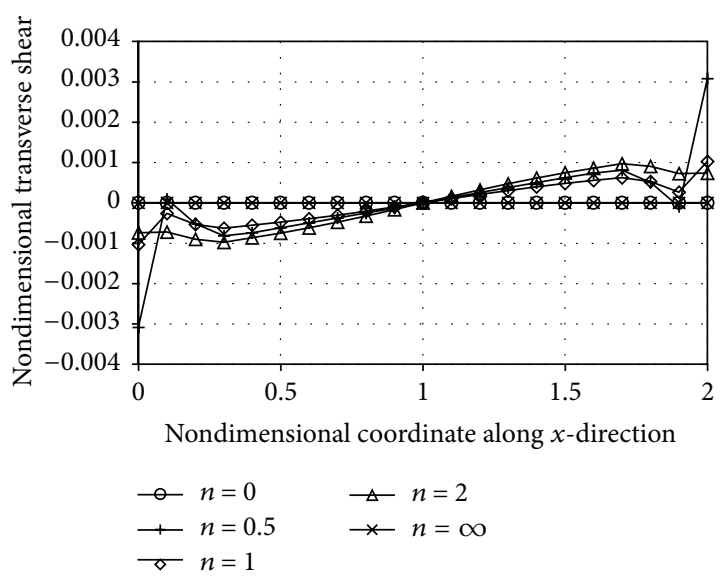

(b) Sinusoidal loadings

FIGURE 15: Transverse shear stress distribution along the $z$-direction of HA/Ti FG plates under thermal loadings. 


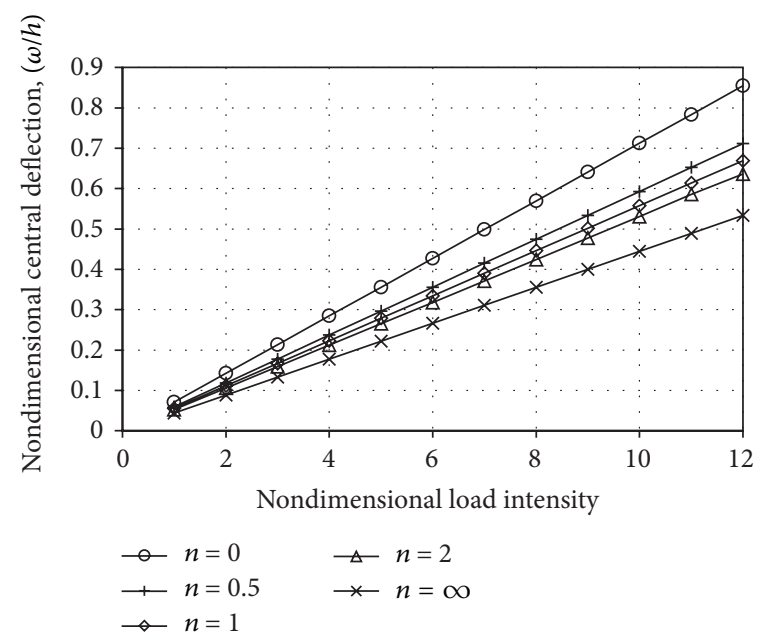

(a) Constant loadings

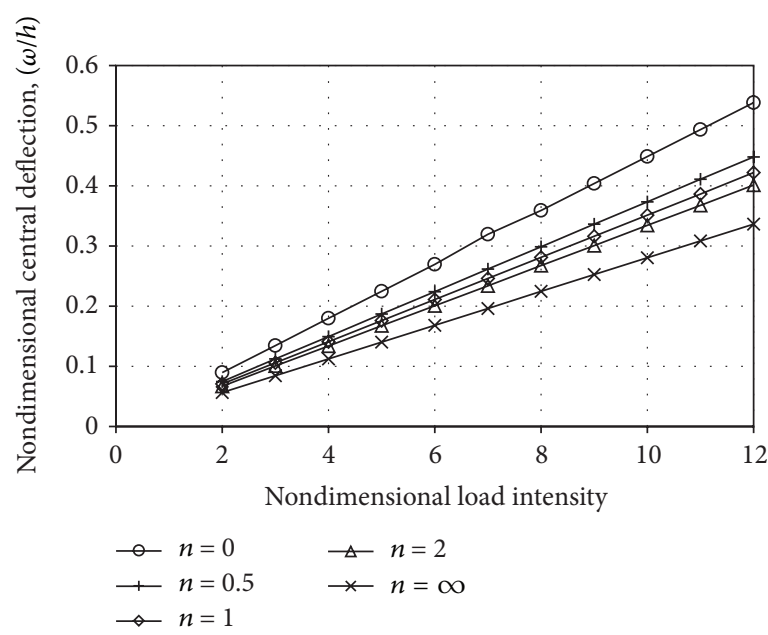

(b) Sinusoidal loadings

FIgURE 16: Nondimensional central deflection of HA/Ti FG plates versus nondimensional load intensity (without thermal loadings).
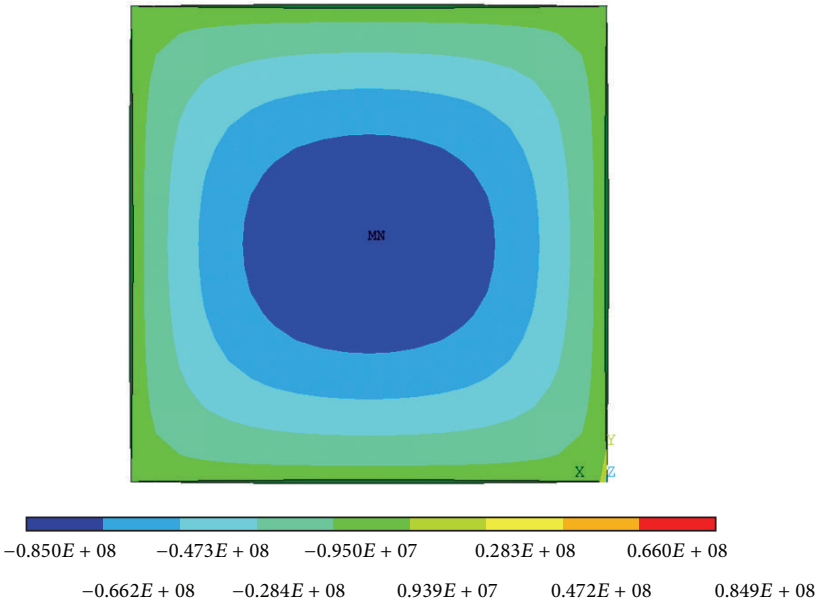

(a) $n=0$
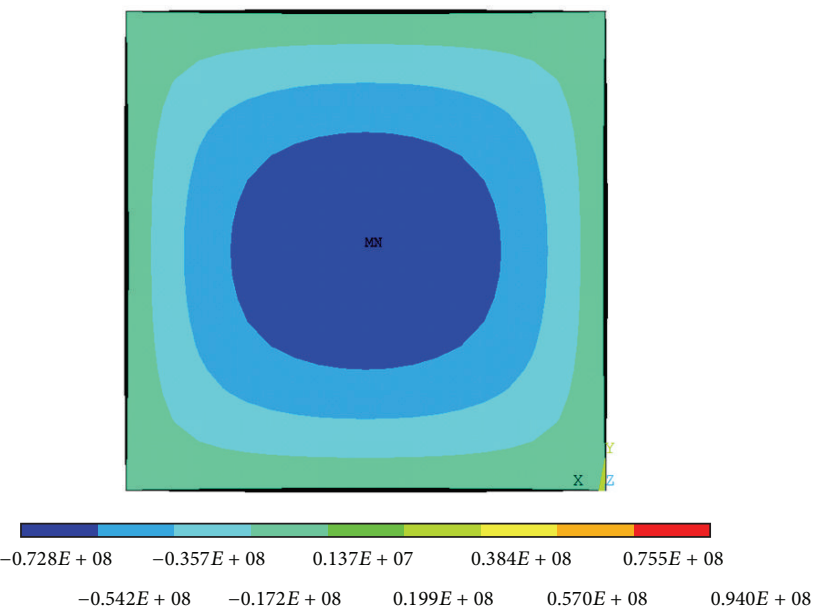

(c) $n=2$
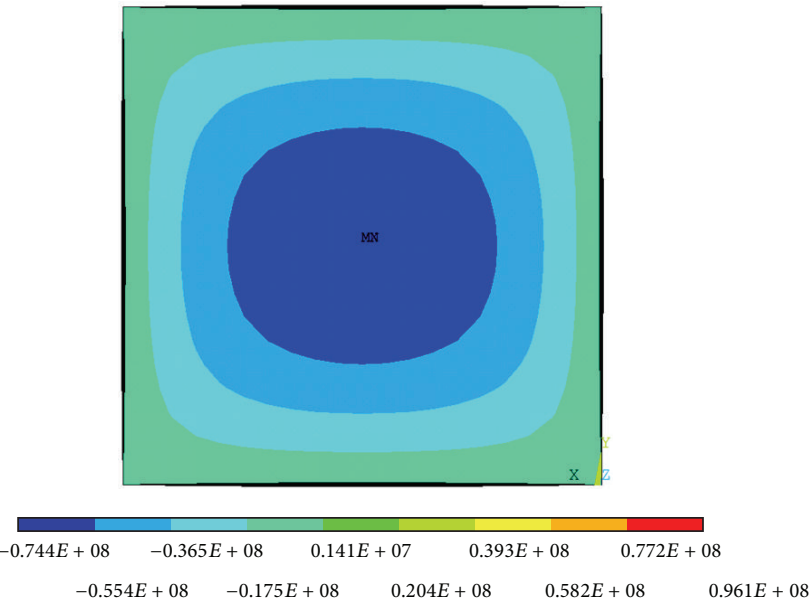

(b) $n=1$
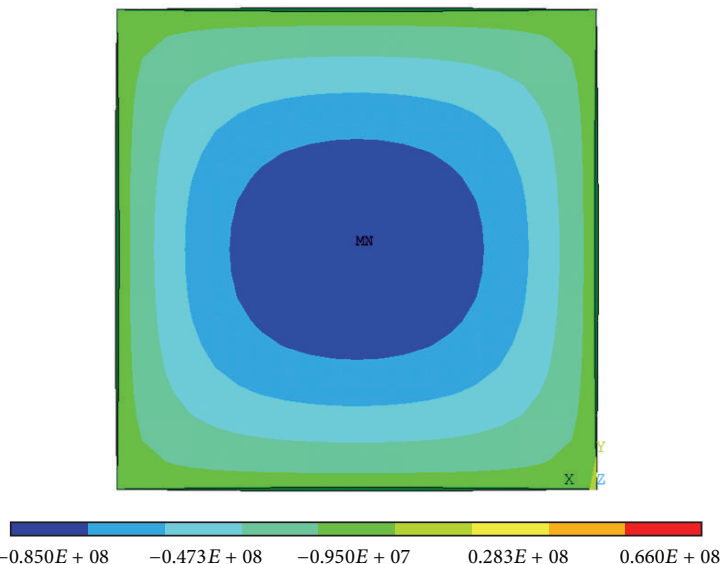

$-0.662 E+08 \quad-0.284 E+08 \quad 0.939 E+07 \quad 0.472 E+08 \quad 0.849 E+08$

(d) $n=\infty$

FIGURE 17: Normal stress distribution at the top surface of HA/Ti FG plates under mechanical loadings. 

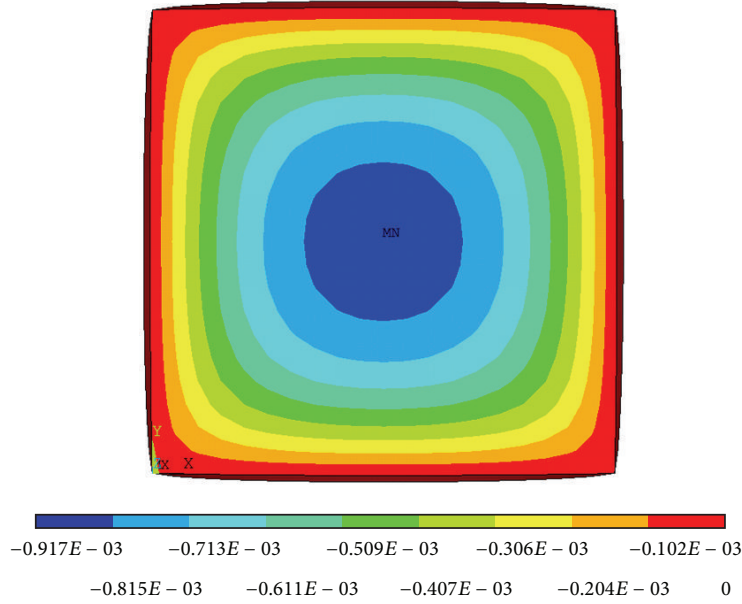

(a) $\bar{P}=1$

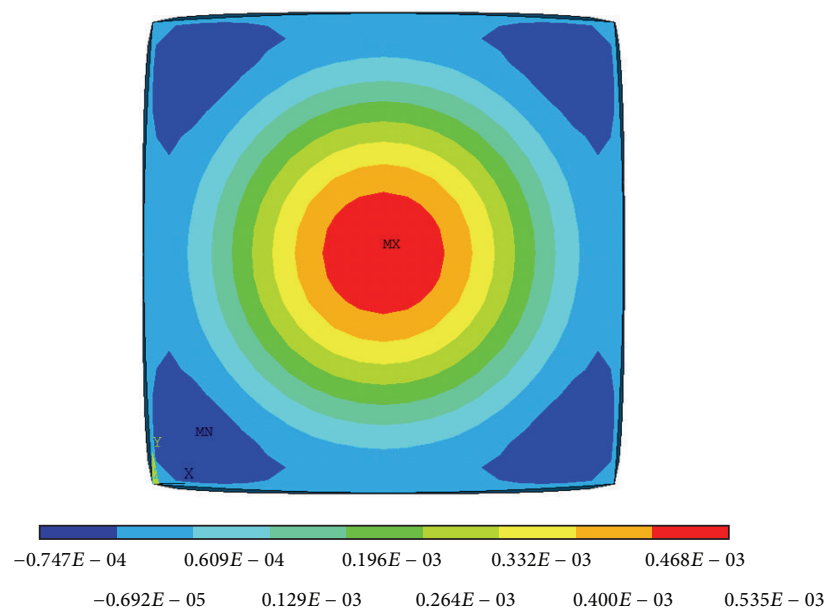

(c) $\bar{P}=3$

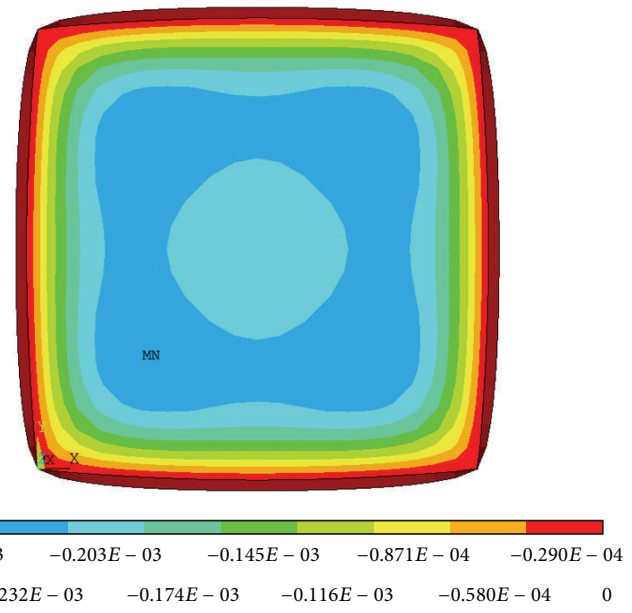

(b) $\bar{P}=2$

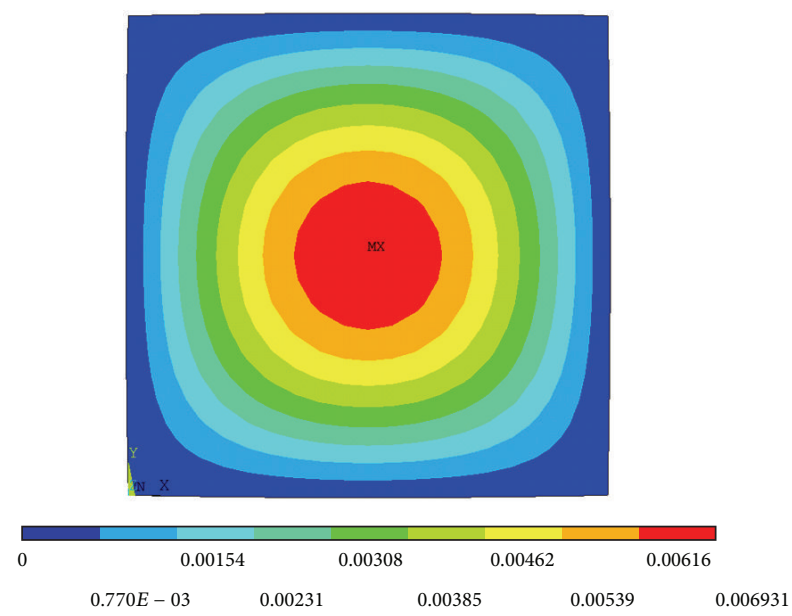

(d) $\bar{P}=12$

FIGURE 18: Deflection of HA/Ti FG plates subjected to coupled thermomechanical loadings.

For the thermoelastic behavior simulation, the FG plates are imposed on a nondimensional load intensity that is the interval of $\{1,12\}$ simultaneously with thermal loadings. The thermoelastic displacement field of HA/Ti FG plates under various load intensity values is illustrated in Figure 18.

It is observed that when subjected to load intensity of $\bar{P}=1$ and 2 , the maximum deflection contour appears at the location near the surface of the FG plates. However, when the higher load intensity $(\bar{P} \geq 3)$ is applied, the maximum deflection contour moves to the center location of the FG plates. These results show that the displacement response of $\mathrm{HA} / \mathrm{Ti}$ FG plates subjected to thermomechanical loadings differs from those subjected to thermal or mechanical individual loading. The thermal excitation on the pressure-loaded plates leads to either the shrinkage or expansion of the FG plates. The nondimensional central deflections of HA/Ti FG plates with various grading parameters, $n$, under thermomechanical loading are summarized in Table 7.

The negative values indicated in Table 7 show the difference between the displacement response induced by the mechanical loadings and that induced by the thermomechanical loadings. The property averaging in FG plates leads to the intermediate deflection values given in Table 7. Figure 19 shows the relationship between the load intensity given on the top surface of the FG plates and the displacement response of the plates. The positive and negative values of deflection given in Table 6 lead to the intersection point shown in Figure 19.

The variation of normal stress field distribution along the thickness of HA/Ti FG plates with various grading parameters, $n$, is shown in Figure 20. The maximum compressive stress is located at the HA top surface and increases as the ratio $E_{U} / E_{L}$ increases. The maximum tensile stress that is found at the Ti bottom surface of FG plates is lower than that of homogenous plates. Figure 21 displays the normal stress field distribution in FG plates with various grading parameters. The most significant aspect of the contour is that the normal stress distributions of FG plates differ from those in isotropic plates. 
TABLE 7: Nondimensional central deflection of HA/Ti FG plates versus nondimensional load intensity (coupled thermomechanical loadings).

\begin{tabular}{|c|c|c|c|c|c|c|c|c|c|c|}
\hline \multirow{3}{*}{$\bar{P}$} & \multicolumn{10}{|c|}{ Nondimensional central deflection $\bar{\omega}$} \\
\hline & \multicolumn{2}{|c|}{ HA } & \multicolumn{2}{|c|}{$n=0.5$} & \multicolumn{2}{|c|}{$n=1$} & \multicolumn{2}{|c|}{$n=2$} & \multicolumn{2}{|c|}{$\mathrm{Ti}$} \\
\hline & Constant & Functional & Constant & Functional & Constant & Functional & Constant & Functional & Constant & Functional \\
\hline 1 & -0.0893 & -0.0618 & -0.0882 & -0.0614 & -0.0834 & -0.0583 & -0.0795 & -0.0555 & -0.0731 & -0.0502 \\
\hline 2 & -0.0189 & -0.0170 & -0.0289 & -0.0241 & -0.0277 & -0.0232 & -0.0264 & -0.0221 & -0.0286 & -0.0222 \\
\hline 3 & 0.0532 & 0.0279 & 0.0304 & 0.0133 & 0.0281 & 0.0199 & 0.0266 & 0.0113 & 0.0159 & 0.0059 \\
\hline 4 & 0.1244 & 0.0727 & 0.0897 & 0.0506 & 0.0839 & 0.0471 & 0.0797 & 0.0447 & 0.0604 & 0.0339 \\
\hline 5 & 0.1956 & 0.1175 & 0.1489 & 0.0880 & 0.1397 & 0.0822 & 0.1327 & 0.0781 & 0.1048 & 0.0619 \\
\hline 6 & 0.2669 & 0.1624 & 0.2082 & 0.1252 & 0.1955 & 0.1173 & 0.1857 & 0.1114 & 0.1493 & 0.0899 \\
\hline 7 & 0.3381 & 0.2072 & 0.2675 & 0.1626 & 0.2513 & 0.1524 & 0.2388 & 0.1448 & 0.1939 & 0.1179 \\
\hline 8 & 0.4094 & 0.2521 & 0.3268 & 0.1999 & 0.3071 & 0.1876 & 0.2918 & 0.1782 & 0.2384 & 0.1459 \\
\hline 9 & 0.4806 & 0.2969 & 0.3826 & 0.2373 & 0.3629 & 0.2227 & 0.3449 & 0.2116 & 0.2829 & 0.1740 \\
\hline 10 & 0.5518 & 0.3418 & 0.4455 & 0.2746 & 0.4187 & 0.2578 & 0.3979 & 0.2450 & 0.3274 & 0.2020 \\
\hline 11 & 0.6231 & 0.3867 & 0.5048 & 0.3120 & 0.4745 & 0.2930 & 0.4510 & 0.2784 & 0.3719 & 0.2300 \\
\hline 12 & 0.6943 & 0.4315 & 0.5641 & 0.3493 & 0.5303 & 0.3281 & 0.5040 & 0.3119 & 0.4164 & 0.2580 \\
\hline
\end{tabular}

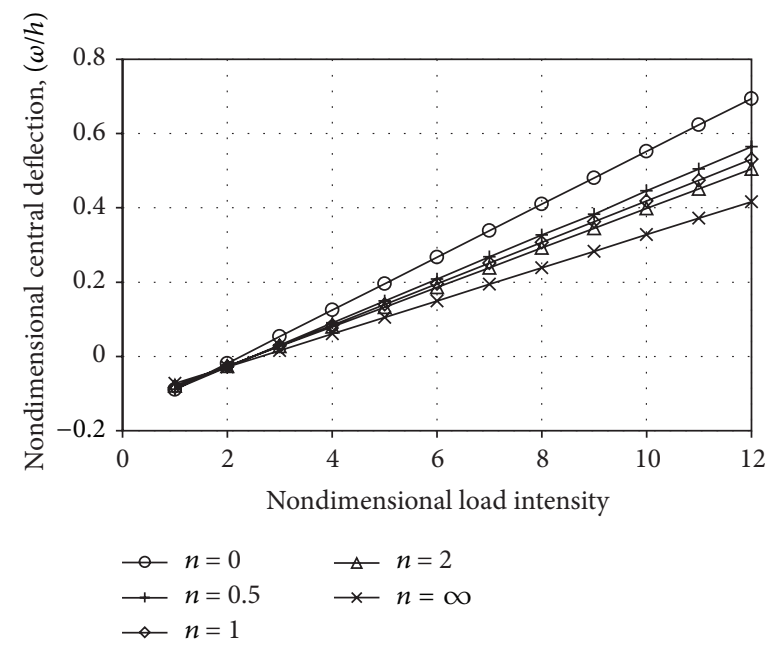

(a) Constant loadings

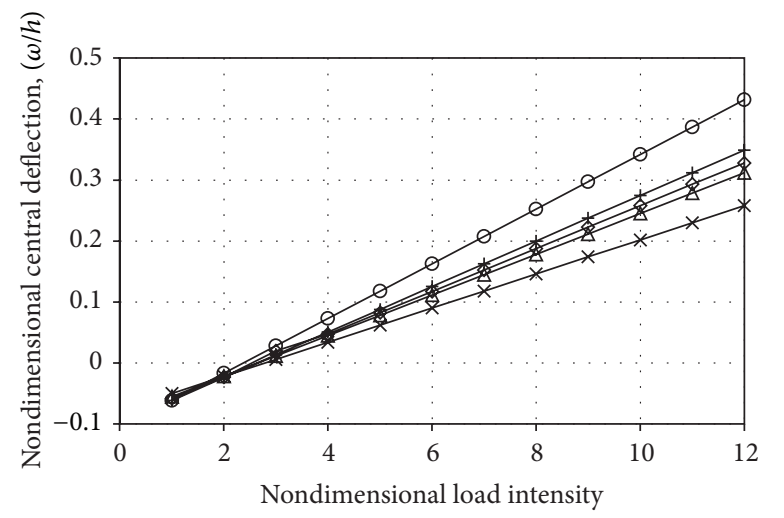

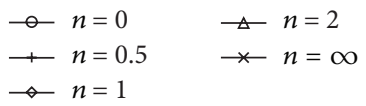

(b) Sinusoidal loadings

FIGURE 19: Nondimensional central deflection of HA/Ti FG plates versus nondimensional load intensity (within thermal loadings).

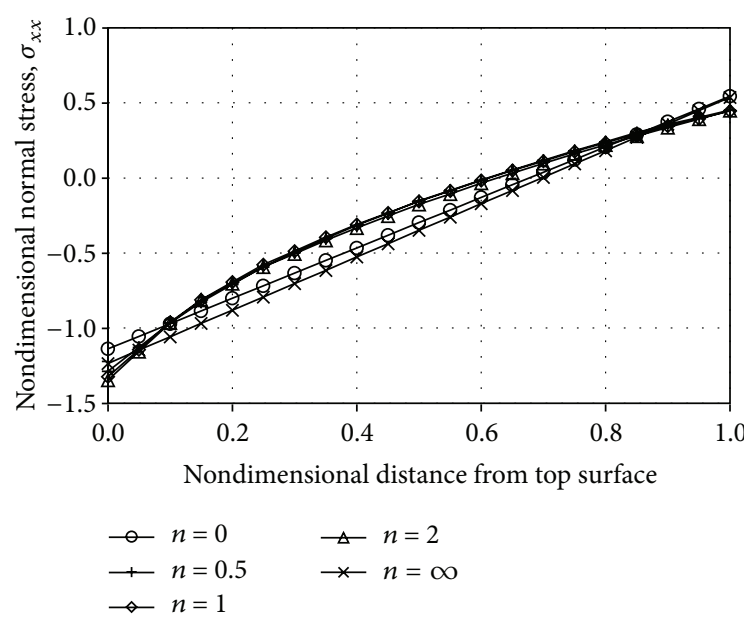

(a) Constant loadings

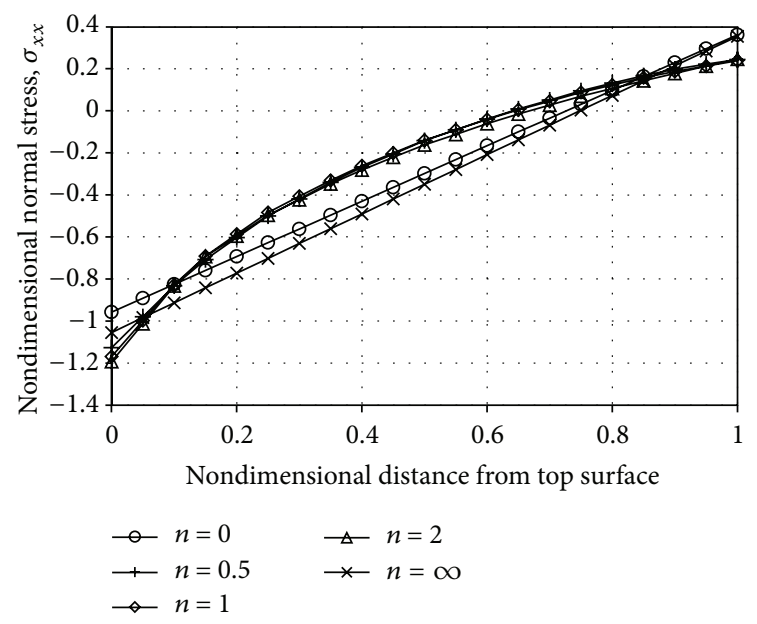

(b) Sinusoidal loadings

FIGURE 20: Nondimensional normal stress distribution along the $z$-direction of HA/Ti FG plates subjected to thermomechanical loading. 


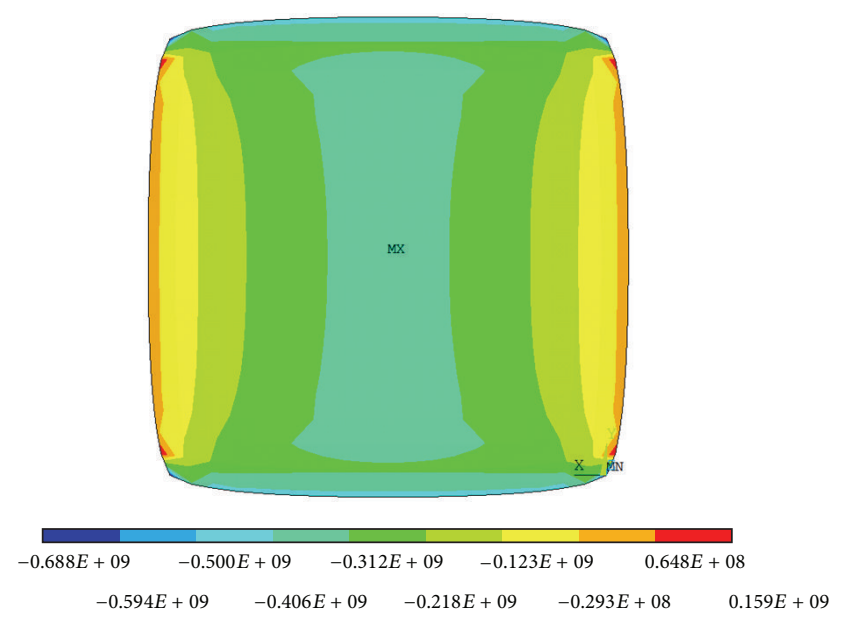

(a) $n=0$

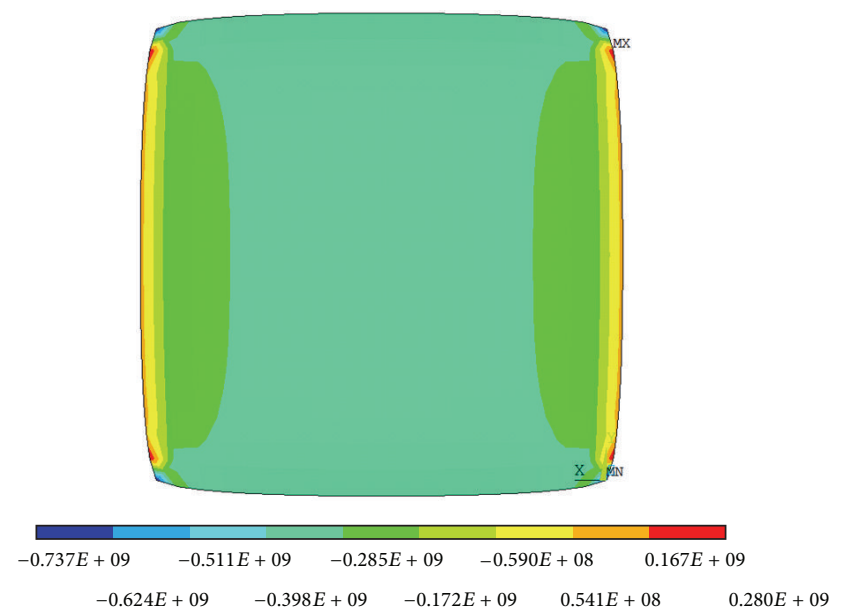

(c) $n=2$

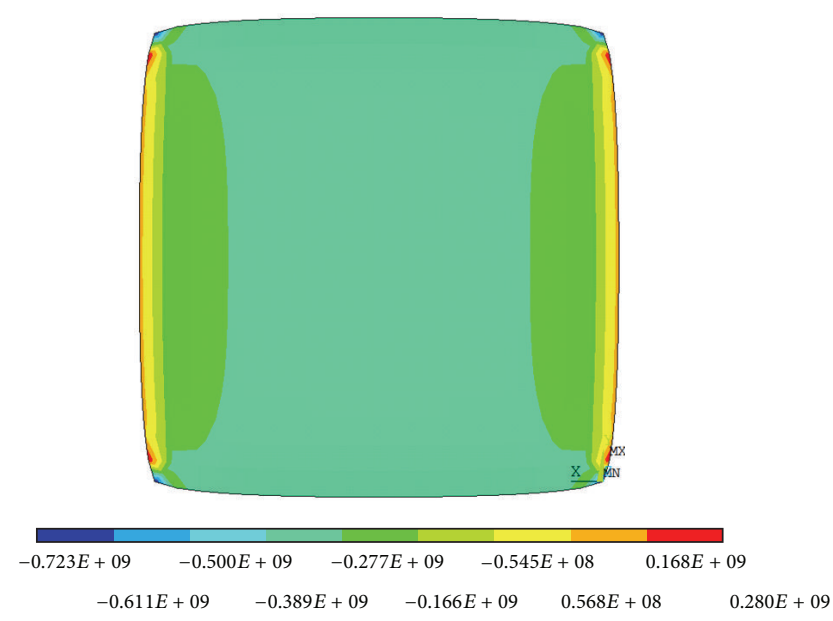

(b) $n=1$

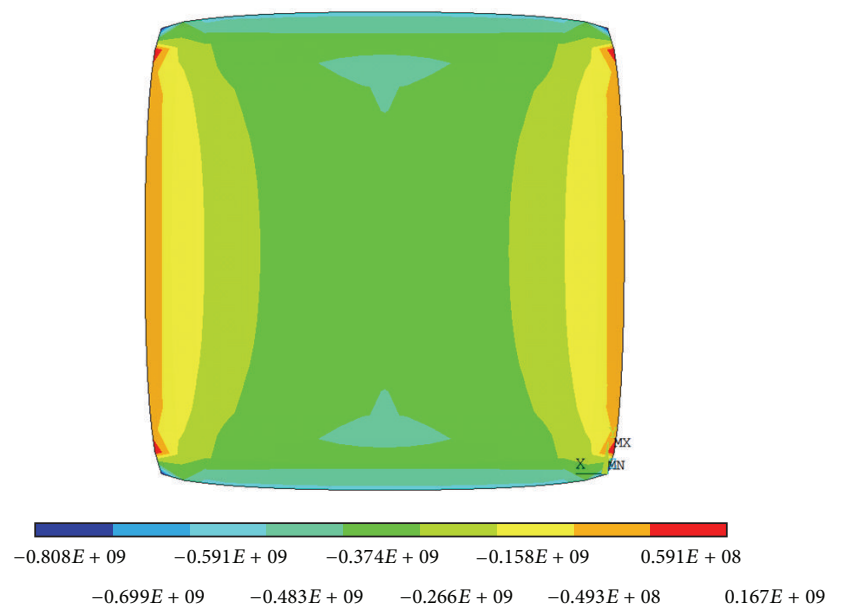

(d) $n=\infty$

FIGURE 21: Normal stress field at the top surface of the HA/Ti FG plates under thermomechanical loadings.

Figure 22 depicts the transverse shear stress distribution in HA/Ti FG plates with various grading parameters under thermomechanical loading. The different shear stress contours between homogeneous and FG plates lead to the conclusion that the properties' gradation in FGMs has impression on the transverse shear stress response of FGMs subjected to coupled thermomechanical loadings. The nondimensional transverse shear stress distribution along the thickness and at the middle plane of $\mathrm{HA} / \mathrm{Ti}$ FG plates with various grading parameters subjected to coupled thermomechanical loading is indicated in Figures 23 and 24, respectively.

It is obvious that the transverse shear stress distribution in the middle plane is more consistent than that along the thickness of the FG plates. This is why the thickness parameter of the FGM layer is often considered during the design of an FGM structure. In this study, the stepwise built connection type of the FG plate layers leads to significant shear stress distribution, which consists of both negative and positive values. The larger layer number is required in order to minimize the shear stress field in the FG plates.

\section{Conclusion}

FEM modeling and analysis of thermomechanical problems of a rectangular HA/Ti FG plate are presented. The effects of different grading indices of constituents on displacement and stress responses of HA/Ti FG plates under thermal, mechanical, and thermomechanical loads have been investigated. From the numerical results obtained, it can be concluded that the present analysis is adequate to observe some relevant fundamental characteristics of temperature profile and stress distributions. Moreover, the following conclusions can be made from the study.

(i) Different loading conditions (thermal, mechanical, or coupled thermomechanical) lead to the different temperature profile, deflection, and stress distribution in $\mathrm{HA} / \mathrm{Ti} \mathrm{FG}$ plates.

(ii) Different values of grading indices show a considerable effect on temperature profile, displacement, and stress fields of HA/Ti FG plates. 

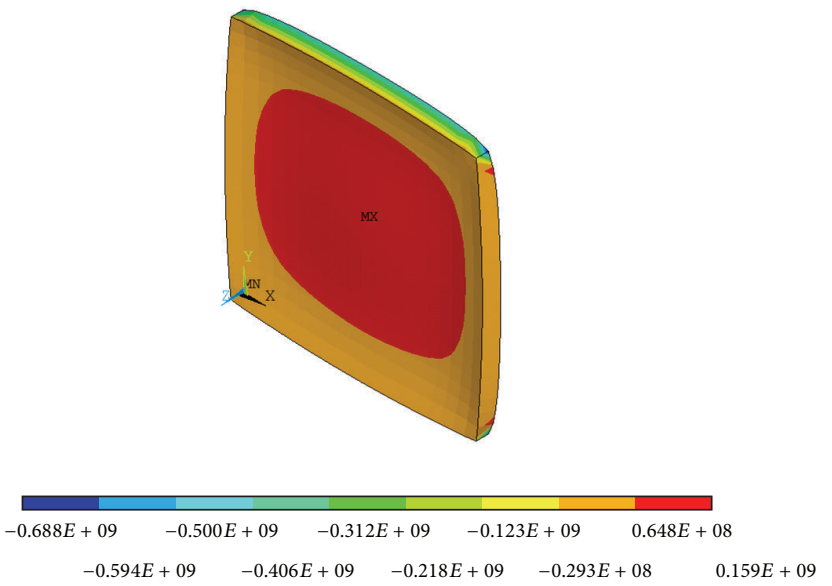

(a) $n=0$
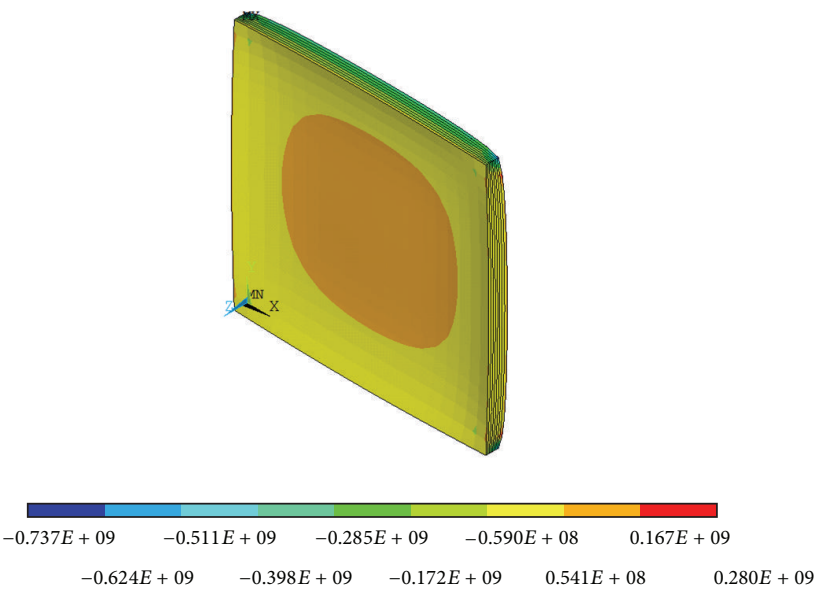

(c) $n=2$
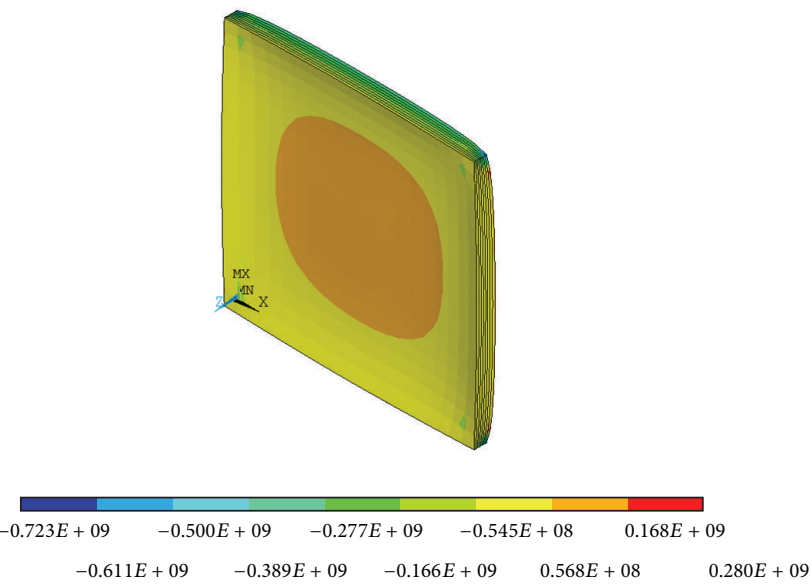

(b) $n=1$
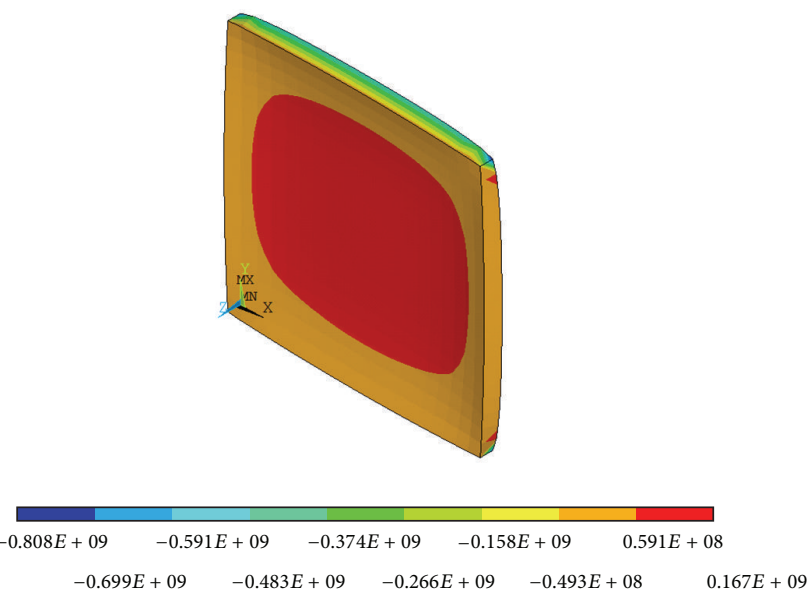

(d) $n=\infty$

FIGURE 22: Transverse shear stress distribution of HA/Ti FG plates under thermomechanical loadings.

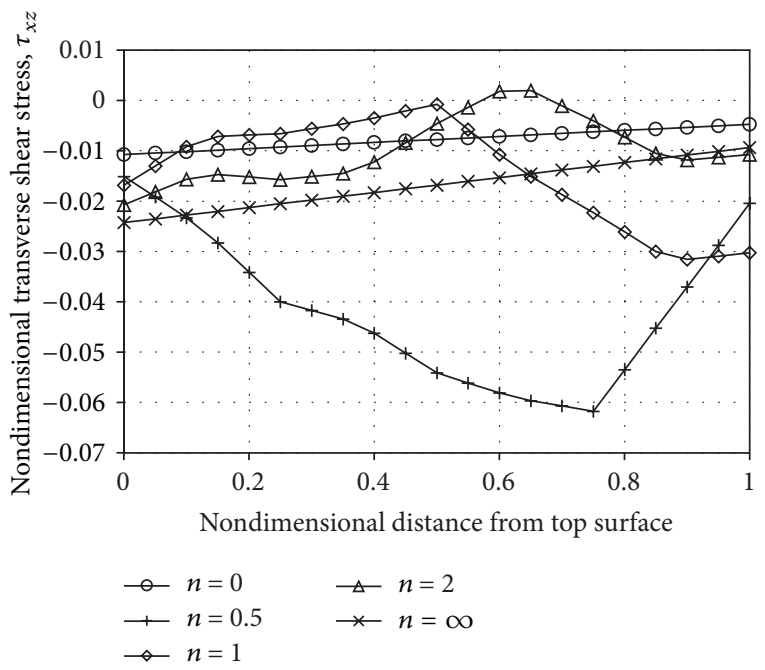

(a) Constant loadings

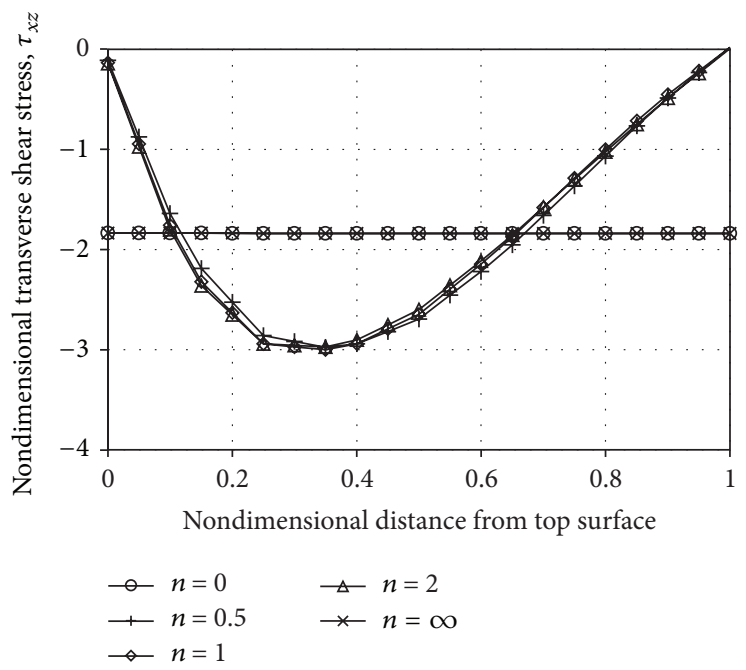

(b) Sinusoidal loadings

FIGURE 23: Nondimensional transverse shear stress along the $z$-direction of HA/Ti FG plates subjected to coupled thermomechanical loadings. 


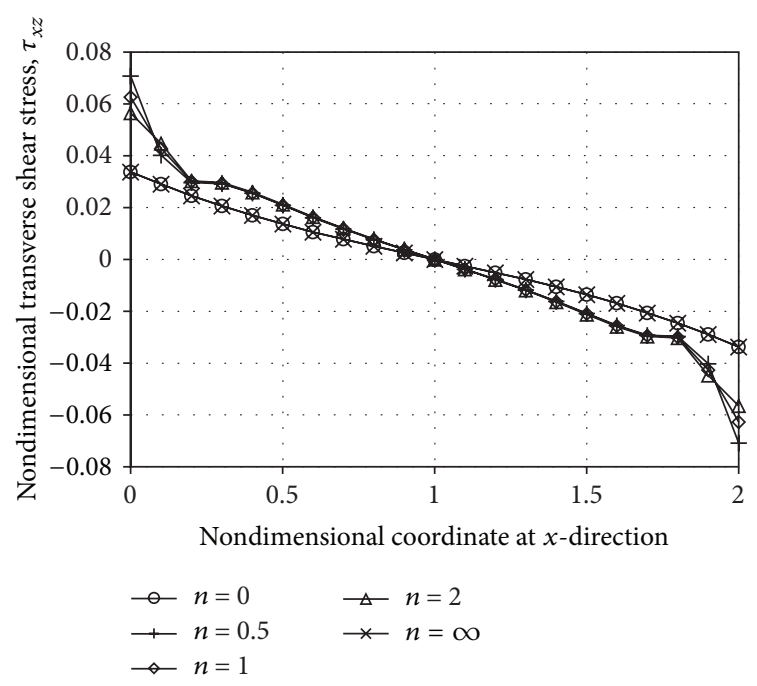

(a) Constant loadings

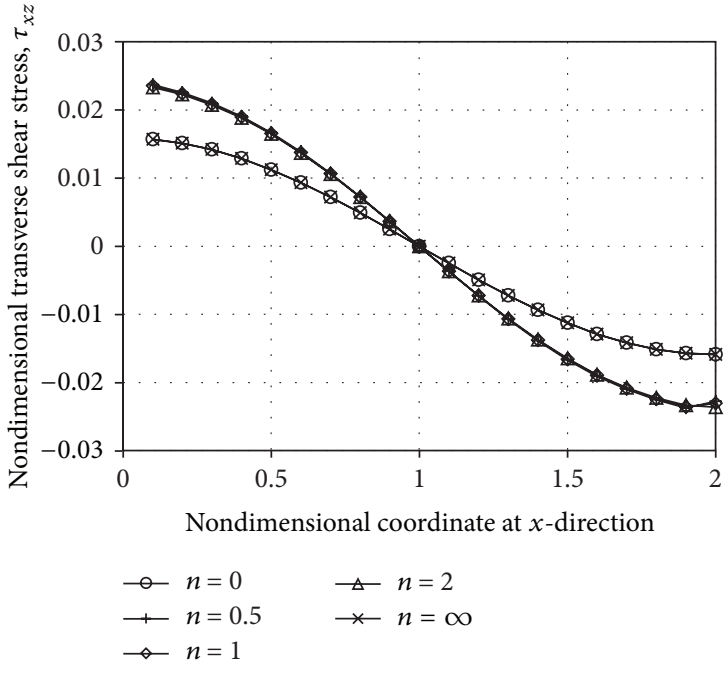

(b) Sinusoidal loadings

Figure 24: Nondimensional transverse shear stress at the middle plane of HA/Ti FG plates subjected to coupled thermomechanical loadings.

(iii) The temperature distribution in FG plates is smaller than that of homogeneous plates.

(iv) Deflection in FG plates subjected to sinusoidal loadings is smaller than those subjected to constant loadings.

(v) The properties' gradation leads to the relaxation in thermal and thermomechanical stress in FG plates.

This study revealed that HA/Ti FGM has a potential application in high thermal resistance materials because it can withstand the extreme surface temperature and the thermal stress.

\section{Conflict of Interests}

The authors declare that there is no conflict of interests regarding the publication of this paper.

\section{Acknowledgments}

This paper was funded by the Deanship of Scientific Research (DSR), King Abdulaziz University, Jeddah, under Grant no. 135-008-D1434. The authors, therefore, acknowledge and thank DSR's technical and financial support. The authors from King Abdulaziz University would like to thank Universiti Malaysia Pahang (UMP) and the team members of the FGMs Research Group, UMP, for their support and for conducting the above research work.

\section{References}

[1] B. Kieback, A. Neubrand, and H. Riedel, "Processing techniques for functionally graded materials," Materials Science and Engineering A, vol. 362, no. 1-2, pp. 81-105, 2003.
[2] H. H. Ibrahim, H. H. Yoo, and K.-S. Lee, "Supersonic flutter of functionally graded panels subject to acoustic and thermal loads," Journal of Aircraft, vol. 46, no. 2, pp. 593-600, 2009.

[3] A. Hosseinzadeh and M. T. Ahmadian, "Application of piezoelectric and functionally graded materials in designing electrostatically actuated micro switches," Journal of Solid Mechanics, vol. 2, no. 2, pp. 179-189, 2010.

[4] G. Mattei, A. Tirella, and A. Ahluwalia, "Functionally graded materials (FGMs) with predictable and controlled gradient profiles: computational modeling and realization," Computer Modeling in Engineering and Sciences, vol. 87, no. 6, pp. 483-504, 2012.

[5] L.-S. Liu, Q.-J. Zhang, and P.-C. Zhai, "The optimization design of metal/ceramic FGM armor with neural net and conjugate gradient method," Materials Science Forum, vol. 423-425, pp. 791-796, 2003.

[6] S. N. S. Jamaludin, F. Mustapha, D. M. Nuruzzaman, T. M. Y. T. Ya, and S. Basri, "Finite element calculation of residual thermal stresses for functionally graded hydroxyapatite-titanium plate design," Academic Platform Journal of Engineering and Science, vol. 1, no. 2, pp. 1-10, 2013.

[7] S. N. S. Jamaludin, F. Mustapha, D. M. Nuruzzaman, and S. Basri, "A review on the fabrication techniques of functionally graded ceramic-metallic materials in advanced composites," Scientific Research and Essays, vol. 8, pp. 828-840, 2013.

[8] H.-S. Shen and N. Noda, "Postbuckling of FGM cylindrical shells under combined axial and radial mechanical loads in thermal environments," International Journal of Solids and Structures, vol. 42, no. 16-17, pp. 4641-4662, 2005.

[9] H. Matsunaga, "Stress analysis of functionally graded plates subjected to thermal and mechanical loadings," Composite Structures, vol. 87, no. 4, pp. 344-357, 2009.

[10] A. Alibeigloo, "Exact solution for thermo-elastic response of functionally graded rectangular plates," Composite Structures, vol. 92, no. 1, pp. 113-121, 2010. 
[11] Y. Kiani and M. R. Eslami, "Thermomechanical buckling of temperature-dependent FGM beams," Latin American Journal of Solids and Structures, vol. 10, no. 2, pp. 223-246, 2013.

[12] P. Zhu, L. W. Zhang, and K. M. Liew, "Geometrically nonlinear thermomechanical analysis of moderately thick functionally graded plates using a local Petrov-Galerkin approach with moving Kriging interpolation," Composite Structures, vol. 107, pp. 298-314, 2014.

[13] L. W. Zhang, P. Zhu, and K. M. Liew, “Thermal buckling of functionally graded plates using a local Kringing meshless method," Composite Structures, vol. 108, pp. 472-492, 2014.

[14] K. M. Liew, Z. X. Lei, J. L. Yu, and L. W. Zhang, "Postbuckling of carbon nanotube-reinforced functionally graded cylindrical panels under axial compression using meshless approach," Computer Methods in Applied Mechanics and Engineering, vol. 268, pp. 1-17, 2014.

[15] L. W. Zhang, Z. X. Lei, K. M. Liew, and J. L. Yu, "Static and dynamic of carbon nanotube reinforced functionally graded cylindrical panels," Composite Structures, vol. 111, pp. 205-212, 2014.

[16] T. Nomura, H. Moriguchi, K. Tsuda, K. Isobe, A. Ikegaya, and K. Moriyama, "Material design method for the functionally graded cemented carbide tool," International Journal of Refractory Metals and Hard Materials, vol. 17, no. 6, pp. 397-404, 1999.

[17] E. Carrera, S. Brischetto, and A. Robaldo, "Variable kinematic model for the analysis of functionally graded material plates," AIAA Journal, vol. 46, no. 1, pp. 194-203, 2008.

[18] Y. Miyamoto, W. A. Kaysser, B. H. Rabin, A. Kawasaki, and R. G. Ford, Functionally Graded Materials: Design, Processing and Applications, Kluwer Academic Publishers, London, UK, 1999.

[19] V. Birman and L. W. Byrd, "Modeling and analysis of functionally graded materials and structures," Applied Mechanics Reviews, vol. 60, no. 1-6, pp. 195-216, 2007.

[20] J. N. Reddy, "Analysis of functionally graded plates," International Journal for Numerical Methods in Engineering, vol. 47, no. 1-3, pp. 663-684, 2000.

[21] A. Ghosh and I. Reimanis, Functionally Graded Materials: Manufacture, Properties and Applications, vol. 76 of Ceramic Transactions, American Ceramic Society, 1997.

[22] C. S. Lee, S.-H. Ahn, L. C. DeJonghe, and G. Thomas, "Effect of functionally graded material (FGM) layers on the residual stress of polytypoidally joined $\mathrm{Si}_{3} \mathrm{~N}_{4}-\mathrm{Al}_{2} \mathrm{O}_{3}$," Materials Science and Engineering A, vol. 434, no. 1-2, pp. 160-165, 2006.

[23] C. S. Lee, S.-G. Kim, S.-H. Ahn, L. C. DeJonghe, and G. Thomas, "Three dimensional analysis of thermal stress and prediction of failure of polytypoidally joined $\mathrm{Si}_{3} \mathrm{~N}_{4}-\mathrm{Al}_{2} \mathrm{O}_{3}$ Functionally Graded Material (FGM)," Materials Transactions, vol. 48, no. 9, pp. 2489-2493, 2007.

[24] M. K. Apalak and R. Gunes, "Thermal residual stress analysis of $\mathrm{Ni}-\mathrm{Al}_{2} \mathrm{O}_{3}, \mathrm{Ni}-\mathrm{TiO}_{2}$, and Ti-SiC functionally graded composite plates subjected to various thermal fields," Journal of Thermoplastic Composite Materials, vol. 18, no. 2, pp. 119-152, 2005.

[25] C. Chu, J. Zhu, Z. Yin, and P. Lin, "Optimal design and fabrication of hydroxyapatite-Ti asymmetrical functionally graded biomaterial," Materials Science and Engineering A, vol. 348, no. 1-2, pp. 244-250, 2003.

[26] H. H. Moroi, K. Okimoto, R. Moroi, and Y. Terada, "Numeric approach to the biomechanical analysis of thermal effects in coated implants," The International Journal of Prosthodontics, vol. 6, no. 6, pp. 564-572, 1993.
[27] G. Ruseska, E. Fidancevska, and J. Bossert, "Mechanical and thermal-expansion characteristics of $\mathrm{Ca}_{10}\left(\mathrm{PO}_{4}\right)_{6}(\mathrm{OH})_{2}$ $\mathrm{Ca}_{3}\left(\mathrm{PO}_{4}\right)_{2}$ composites," Science of Sintering, vol. 38, no. 3, pp. 245-253, 2006.

[28] J. N. Reddy and Z.-Q. Cheng, "Three-dimensional thermomechanical deformations of functionally graded rectangular plates," European Journal of Mechanics-A/Solids, vol. 20, no. 5, pp. 841-855, 2001.

[29] A. E. Alshorbagy, S. S. Alieldin, M. Shaat, and F. F. Mahmoud, "Finite element analysis of the deformation of functionally graded plates under thermomechanical loads," Mathematical Problems in Engineering, vol. 2013, Article ID 569781, 13 pages, 2013.

[30] G. Srinivas, U. S. Prasad, M. Manikandan, and A. P. Kumar, "Simulation of traditional composites under thermal loads," Research Journal of Recent Sciences, vol. 2, pp. 273-278, 2013. 


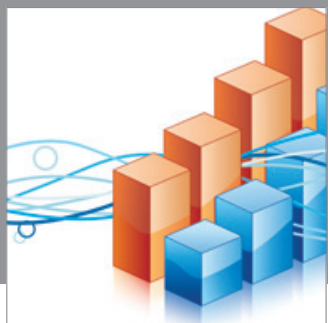

Advances in

Operations Research

mansans

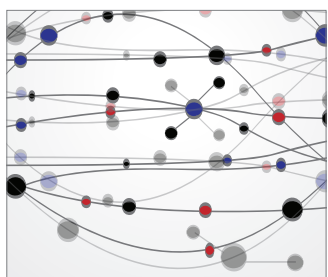

The Scientific World Journal
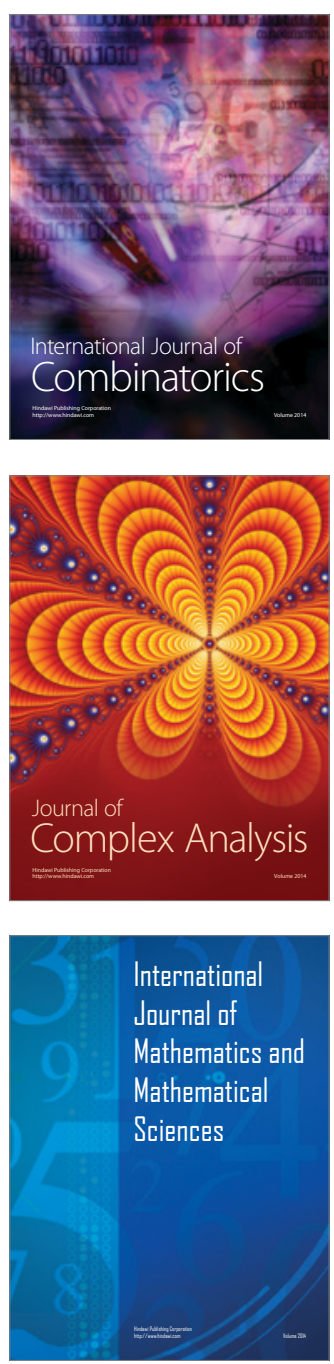
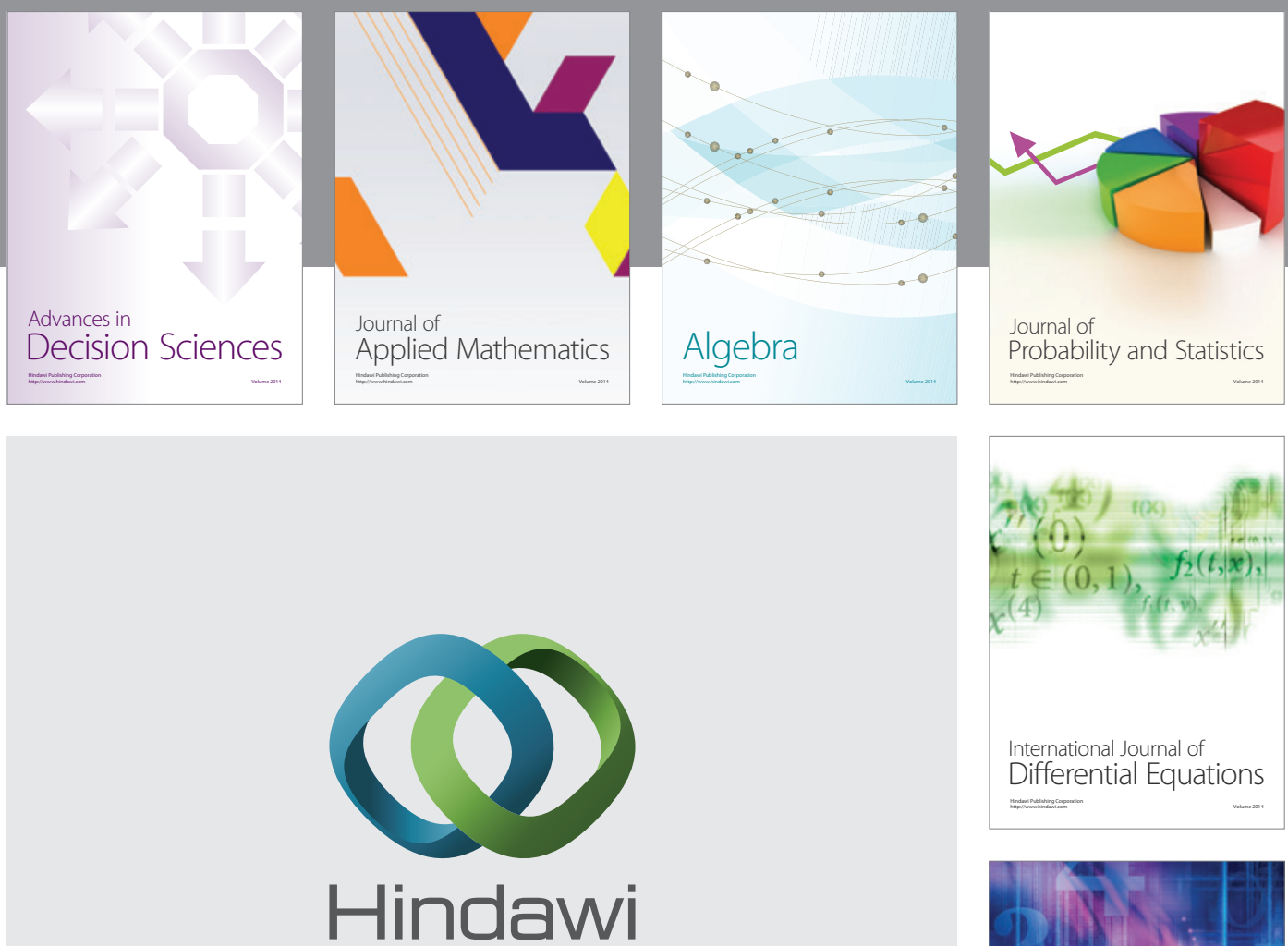

Submit your manuscripts at http://www.hindawi.com
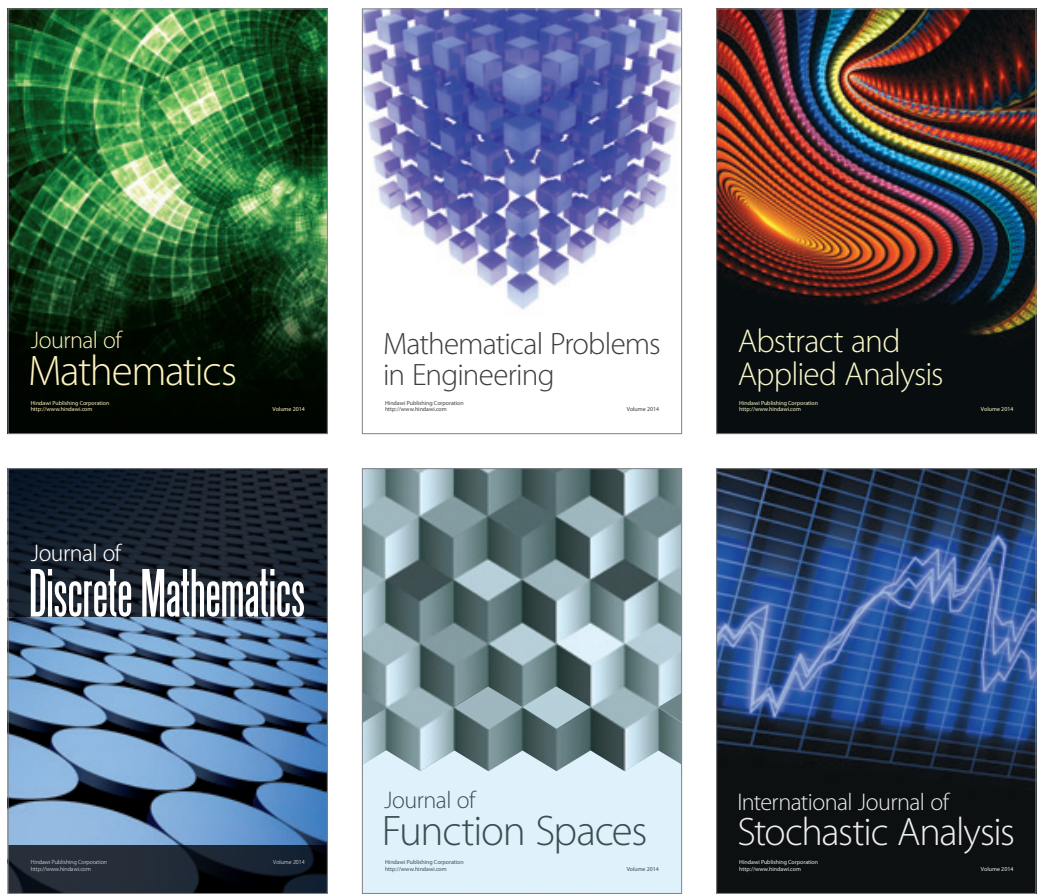

Journal of

Function Spaces

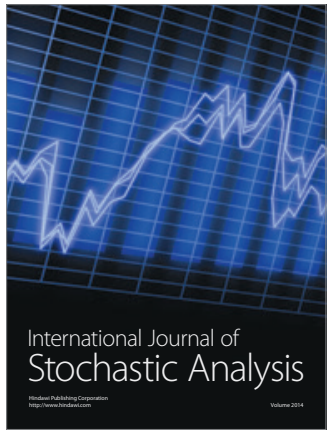

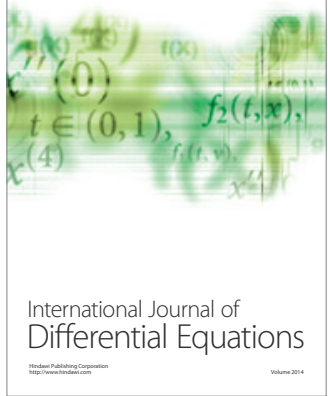
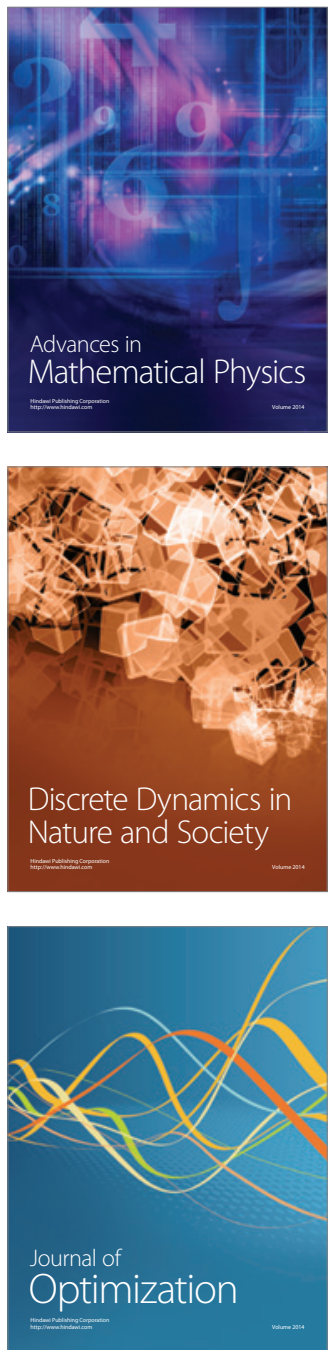